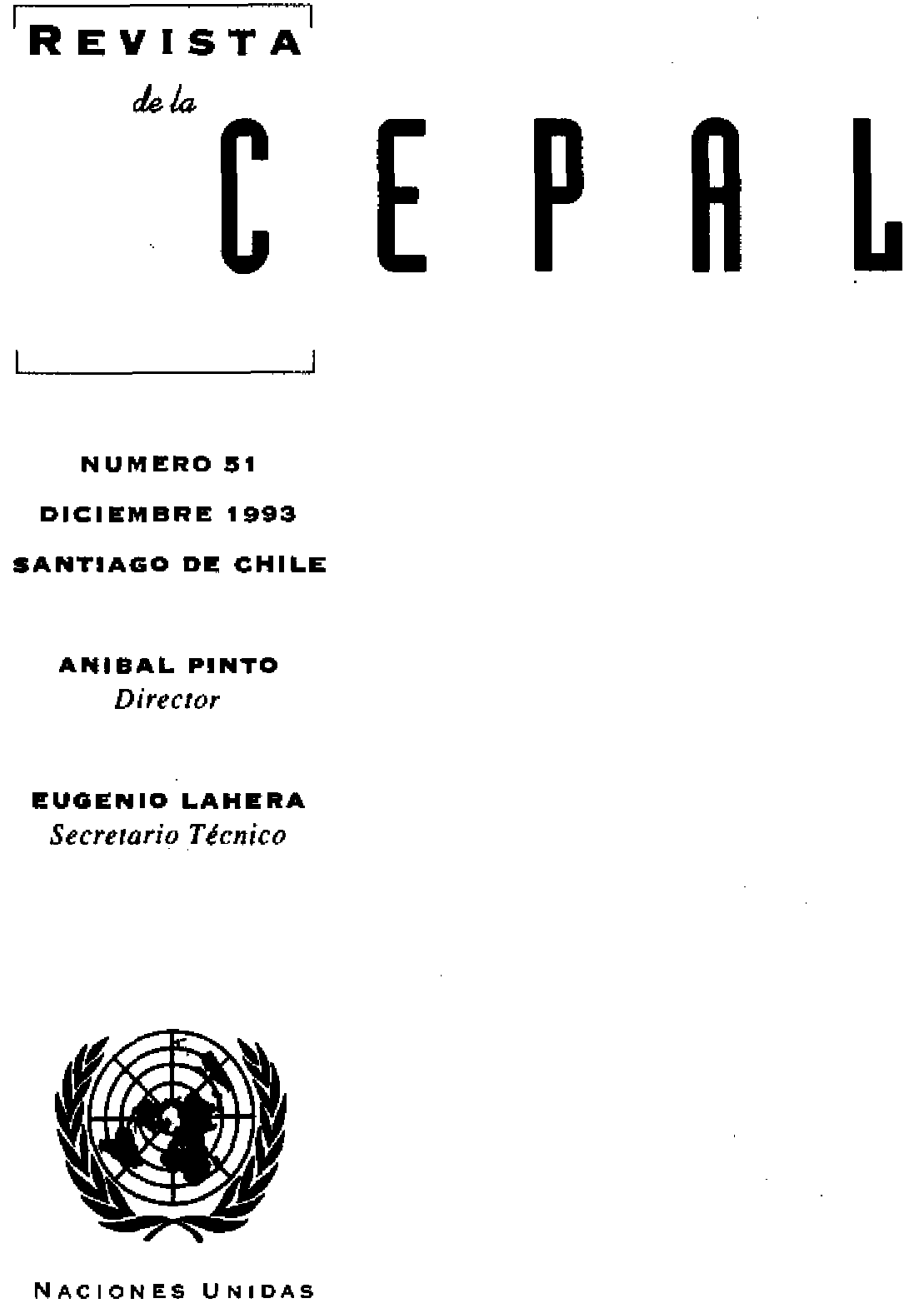


Inauguración de la Sala Fernando Fajnzylber y lanzamiento de la Revista de la CEPAL N² $\mathbf{5 0}$

Gert Rosenthal y Alejandro Foxley

Las transnacionales y la Industria en los paises en desarrollo

Michael Mortimore

¿Dónde estamos en política Industrial?

El desafío de la competitividad Industrial

Rudolf M. Buitelaar y Leonard Mertens

Integración y desintegración social rural

Martine Dirven

Los pueblos Indigenas y la modernidad

John Durston

Productividad y trabajo de la mujer en los Estados Unidos

Inés Bustillo y Nancy S. Barrett

Efectos de las corrientes de capltal sobre la base monetarla

111

Helmut Reisen

Viejas y nuevas políticas comerclales

Daniel Lederman

Integración y desviación de comerclo

Renato Baumann

Integración europea y comerclo latinoamericano

Miguel Izan

El actual debate sobre los recursos naturales

Fernando Sánchez Albavera

Orlentaclones para los colaboradores de la Revista de la CEPAL 


\section{Las transnacionales \\ y la industria en los países en desarrollo}

\section{Michael Mortimore}

Oficial de Asuntos Transnacionales de la Unidad Conjunta CEPAL/UNCTAD de Empresas Transnacionales.
La construcción de un nuevo orden industrial internacional dominado por un núcleo de grandes empresas transnacionales por lo general dificulta la vida de la gran mayoría de los paŕses en desarrollo que, por no estar en condiciones de competir eficazmente, enfrentan una marginalización todavía mayor. Hoy las empresas transnacionales pueden influir considerablemente en la competitividad internacional y, por lo tanto, en la f́ndole de la incorporación de los páses en desarrollo en el nuevo sistema productivo internacional en vías de integración. El país de origen y la forma que toman la inversión extranjera directa y la transferencia de tecnología determinan en gran medida los efectos de las empresas transnacionales en la industria del pais huésped. La experiencia de algunos de los países recién industrializados de Asia indica que la inversión extranjera directa y la transferencia de tecnología desde Japón, que se da en forma de participaciones minoritarias en el capital u otro tipo de participaciones distintas del capital social en las empresas locales, ha sido un elemento muy importante para mejorar la competitividad internacional de esos países y la modernización tecnológica constante de sus industrias. La experiencia de América Latina - con inversión extranjera directa y tecnologra estadounidenses de menor dinamismo que usualmente revistio la forma de subsidiarias o filiales con participación mayoritaria de capital extranjero- tendio a fortalecer los sesgos de la industrialización orientada hacia el interior mediante la sustitución de importaciones y contribuyó poco a mejorar la competitividad de la industria latinoamericana, que sufrío una consiguiente marginalización progresiva tanto desde una perspectiva internacional como empresarial. 


\section{I}

\section{Introducción}

Actualmente está tomando forma un nuevo orden industrial internacional, lo que tendrá fuertes repercusiones en los países en desarrollo (Mortimore, 1992). Este nuevo orden atañe primordialmente a un núcleo de unos pocos miles de empresas transnacionales que operan en una media docena de industrias tecnológicamente avanzadas y en otra media docena que se halla en proceso de reestructuración industrial. Alrededor de este núcleo está surgiendo un sistema productivo internacional integrado. Este sistema se centra en la Tríada, es decir, los enormes merçados de la Comunidad Europea, América del Norte y Japón, y se extiende hacia agrupaciones regionales de países en desarrollo asociados con cada uno de estos tres principales mercados (UNCTAD, 1993; CET, 1991a).

La tecnología es hoy el elemento crucial en la definición de las ventajas comparativas. ${ }^{1}$ Se observan claras indicaciones del nuevo orden internacional en los procesos de globalización y especialización que caracterizan las corrientes del comercio exterior, y en los procesos de globalización y regionalización vinculados a los flujos de la inversión extranjera directa. Dentro de la Tríada, las empresas transnacionales japonesas han efectuado grandes progresos, primordialmente a expensas de sus contrapartes norteamericanas y europeas. Sus avances han tenido lugar sobre todo en las industrias tecnológicamente avanzadas y más competitivas a nivel internacional (computadores y equipo de oficina, automóviles, artículos electrónicos, máquinas herramientas, etc.) con las cuales los industriales japoneses han entrado con vigor en los mercados internacionales y están estableciendo nuevas operaciones a nivel internacional o regional.

El incremento de la competencia internacional en las relaciones económicas globales ha hecho que los países en desarrollo reciban en la actualidad menos preferencias de parte de los países de la Organización de Cooperación y Desarrollo Económicos (OCDE) y que al mismo tiempo deban competir con ellos en condiciones más duras. Sólo un grupo relativamente pequeño de países en desarrollo se halla en condiciones de hacerlo. Otro aspecto del nuevo orden industrial internacional es el hecho de que hay segmentos importantes de las actividades manufactureras que están siendo transferidas o asignadas a países en desarrollo que poseen las ventajas competitivas requeridas por el núcleo de empresas transnacionales. Estos países podrían incorporarse al nuevo orden industrial internacional, pero el grado de incorporación dependerá de la índole de las ventajas competitivas ofrecidas por el proceso de industrialización local.

La adopción de decisiones de política a nivel nacional solía ser el elemento determinante del proceso de industrializacion local; pero en el nuevo orden industrial internacional los aspectos más trascendentales del proceso decisorio pasan al núcleo de empresas transnacionales del nuevo sistema integrado de producción internacional. A este respecto, la situación competitiva de los mercados internacionales para los productos de las empresas transnacionales, así como las estrategias empresariales de estas transnacionales destinadas a hacerles frente, tienen precedencia en las decisiones de efectuar inversiones, generar comercio y transferir tecnología que adopta el núcleo de empresas transnacionales. La manera como los gobiernos de los países en desarrollo se adapten a este nuevo orden determinará si su integración en él será de adaptación creativa (flying wild geese) dinámica o de inmovilismo vulnerable (sitting ducks). ${ }^{2}$

\footnotetext{
1 Véanse Cantwell y Dunning, 1991; Chandler, Jr., 1990; Encarnation, 1992; OCDE, 1992; Teece (ed.), 1987 y Thurow, 1992. Respecto de los países en desarrollo, consíltese Ernst y O'Connor, 1989.
}

\footnotetext{
${ }^{2}$ En el artículo original en inglés el autor utiliza un juego de palabras en el que compara flying wild geese (ánsares en vuelo, di námicos y capaces de alejarse del peligro) con sitting ducks (patos inmóviles que son blanco fácil). En su examen de la competitividad internacional el autor relaciona los primeros con el Asia en desarrollo y los segundos con América Latina.
} 


\section{II}

\section{Competitividad internacional: adaptación dinámica del Asia en desarrollo e inmovilismo de América Latina}

Al delinearse el nuevo sistema integrado de producción internacional, unos pocos países en desarrollo se vincularán con determinadas redes regionales de abastecimiento, las que para todos los fines prácticos definirán la forma en que ellos se incorporarán en el nuevo orden industrial. En el pasado, las empresas transnacionales han incorporado de maneras muy diversas a la industria de los países en desarrollo. La experiencia de varios países en desarrollo asiáticos y de la mayoría de los latinoamericanos aporta elementos de juicio a este respecto.

\section{El esquema del Asia en desarrollo}

El cuadro 1 muestra los fundamentos de un esquema conceptual, basado en las obras de Porter y de Ozawa,

CUADRO :

Ventajas competitivas y desarrollo industrial

\begin{tabular}{|c|c|c|}
\hline Etapa de crecimiento industrial & Exportaciones de bienes & $\begin{array}{c}\text { Corrientes de inversion extranjera } \\
\text { directa }\end{array}$ \\
\hline 1. Impulsada por los factores & $\begin{array}{l}\text { Exportaciones basadas en recursos } \\
\text { naturales y con uso intensivo } \\
\text { de mano de obra }\end{array}$ & $\begin{array}{l}\text { Afluencia de inversión extranjera } \\
\text { directa en busca de recursos } \\
\text { naturales y mano de obra barata } \\
\text { (alimentos, textiles, etc.) }\end{array}$ \\
\hline 2. Impulsada por la inversión & $\begin{array}{l}\text { Lo anterior, más exportaciones con } \\
\text { uso intensivo de capital }\end{array}$ & $\begin{array}{l}\text { Af̣luencia de inversión extranjera } \\
\text { directa para producir bienes de } \\
\text { consumo duraderos e intermedios } \\
\text { (productos electrónicos, } \\
\text { automóviles, etc.). Salida hacia } \\
\text { industrias de uso intensivo de factores }\end{array}$ \\
\hline 3. Impulsada por las innovaciones & $\begin{array}{l}\text { Lo anterior, mas bienes de capital y } \\
\text { exportaciones cont uso intensivo de } \\
\text { investigación y desarrollo }\end{array}$ & $\begin{array}{l}\text { Afluencia hacia bienes de capital y } \\
\text { actividades con uso intensivo de } \\
\text { investigación y desarrollo (máquinas } \\
\text { herramientas). Salida hacia } \\
\text { industrias intensivas en inversiones }\end{array}$ \\
\hline 4. Impulsada por la riqueza & da de co & Iad internacional \\
\hline
\end{tabular}

mediante el cual puede interpretarse la experiencia asiática (Porter, 1990; Ozawa, 1992). En esencia, se sugiere que en Asia es posible identificar una trayectoria definida hacia el crecimiento y el desarrollo que está directamente relacionada con las ventajas competitivas que poseen los países en desartollo de esa región. En esa trayectoria se distinguen cuatro etapas de crecimiento industrial, impulsadas respectivamen- te por los factores de producción; por la inversión; por la innovación, y por la riqueza. Con cada etapa se asocian determinados cambios en las modalidades del comercio exterior y de la inversión extranjera directa.

En la primera etapa las únicas ventajas que poseen los países extremadamente pobres, sobrepoblados y subdesarrollados son los recursos naturales y la mano de obra no especializada barata. En esta etapa 
generalmente se inician industrias procesadoras de alimentos, industrias textiles y manufacturas sencillas de cuero y madera, así como operaciones de ensamblaje que utilizan insumos importados. El comercio exterior crece en virtud de las exportaciones emanadas de estas actividades que hacen uso intensivo de los factores de producción, y la inversión extranjera directa llega en busca de recursos naturales y mano de obra barata.

Durante un tiempo el país en desarrollo genera y acumula capital y el proceso de industrialización se concentra cada vez más en la segunda etapa, con actividades que hacen uso más intensivo de capital. Como resultado, a las exportaciones generadas en la primera etapa se suma el comercio exterior que surge de las actividades impulsadas por las inversiones en la producción de bienes de consumo duraderos (productos electrónicos y automóviles) y bienes intermedios (acero, etc.), al comienzo con miras a la sustitución de importaciones, y luego, gradualmente, con miras a competir en el plano internacional. Grupos locales que han llegado a dominar las actividades basadas en el uso intensivo de los factores comienzan a invertir en otros países en desarrollo que ofrecen más ventajas competitivas en estos factores. La inversion extranjera directa que llega se circunscribe a actividades que hacen uso intensivo de capital. En esta segunda etapa son mucho mayores el valor agregado, el incremento de los salarios reales y la complejidad tecnológica de las actividades industriales.

Muy pocos países en desarrollo llegan a la tercera etapa, basada en la innovación. Japón podría considerarse el líder de Asia al respecto. En esta etapa, la tecnología se convierte en el elemento primordial de la capacidad competitiva de los bienes de capital (máquinas herramientas) y de las actividades con uso intensivo de investigación y desarrollo tecnológico (como la fabricación de computadores y semiconductores); con el tiempo, la tecnología necesaria se produce cada vez más a nivel local en vez de transferirse desde el exterior. A medida que se tiene acceso a la tecnología extranjera y que ésta se asimila, se adapta y se mejora, se agregan nuevas exportaciones más complejas -desde el punto de vista tecnológico-que las basadas en la utilización de los factores y la inversión, las que se hacen cada vęz menos dinámicas. La inversión extranjera directa hacia el exterior se dirige a países que ofrecen relativamente más ventajas competitivas en las industrias impulsadas por las inversiones, en las que los grupos locales se han vuelto más eficientes. La inversión extranjera directa afluye para aprovechar las actividades impulsadas por la innovación y la aplicación de tecnología. Igual que en la transición de la primera a la segunda etapa, aumenta el valor agregado, se elevan los salarios reales y se incrementa la complejidad tecnológica. No es preciso referirse aquí a la cuarta etapa, basada en la riqueza, ya que no corresponde a la situación de los países de Asia; sin embargo, se puede relacionar la pérdida de competitividad internacional en esta etapa con la situación de Europa y los Estados Unidos.

En el marco conceptual descrito, el esquema de los ánsares en vuelo concibe el crecimiento y el progreso tecnológico en Asia a semejanza de la formación de saeta que estas aves adoptan al migrar. A la cabeza va el ave que señala el rumbo a la bandada. En Asia, ese papel recae en la industria japonesa, más avanzada desde el punto de vista tecnologico, la que en la etapa impulsada por la innovación va desprendiéndose de las industrias basadas en la inversión (productoras de bienes intermedios e intensivos en capital) y derivándolas hacia los países en desarrollo más adelantados de la región. Así sucedió anteriormente con la industria basada en la mano de obra al dejarse atrás la etapa impulsada por el aprovechamiento de los factores. En este sentido, las economías asiáticas de industrialización reciente (la República de Corea, la provincia china de Taiwán, Hong Kong y Singapur) se alinean en la bandada inmediatamente detrás del Japón. Les siguen algunos miembros de la Asociación de Naciones del Sudeste Asiático (ASEAN) —Indonesia, Malasia, Filipinas y Tailandia - en virtud de las actividades intensivas en mano de obra desplazadas a su vez desde las economías asiáticas de industrialización reciente (EAIR). Puede decirse que China viene más atrás en la bandada y que se hace cargo de operaciones de ensamblaje con mucha exigencia de mano de obra barata y poca de tecnología, en las que los cuatro países mencionados de la ASEAN pierden competitividad relativa.

Como puede apreciarse, el elemento operacional de este esquema es el proceso de aprendizaje asociado con el desarrollo tecnológico, que comienza con la transferencia de la tecnología extranjera original y pasa por etapas de asimilación, absorción, difusión, adaptación, institucionalización, generación e innovación, hasta que la tecnología original (o una versión mejorada de ésta) es nuevamente transferida, esta vez por el país receptor, hacia una economía de menor adelanto tecnológico relativo. Varios países en desarrollo de Asia han mostrado particular saga- 
cidad al utilizar zonas de procesamiento de las exportaciones para iniciar el proceso de transferencia tecnológica, que a la postre lleva a competir en el mercado internacional con el proveedor original de esa tecnología.

El esquema de los ánsares en vuelo, tal como lo aplica Fukusaku, entre otros, a Asia (Fukusaku, 1992) demuestra que algunos países en desarrollo tienen la capacidad de modificar conscientemente la indole estructural de su integración en el sistema de producción internacional en lo relacionado con sus exportaciones de bienes manufacturados, dándoles un contenido mayor de capital humano y tecnología, y menor de recursos naturales y mano de obra no especializada. De este modo, su proceso de industrialización gira alrededor del progreso tecnológico, el que a su vez brinda una mayor base de sustentación y asegura alguna dinámica local del proceso de industrialización en el marco del nuevo orden industrial internacional.

Dicho esquema sugiere también que si hay que imitar a otros para conquistar un lugar en ese nuevo orden, es esencial emular un ejemplo exitoso. En un lapso de medio siglo, Japón pasó de fabricante de textiles a productor de maquinaria textil. A este respecto, los cuatro países asiáticos de industrialización reciente y los cuatro países señalados de la ASEAN no sólo han demostrado que son imitadores astutos, sino que también se han convertido en duros competidores para su mentor japonés, de lo cual los automóviles coreanos o los computadores taiwaneses son ejemplo suficiente.

\section{Una comparación con América Latina}

La magnitud de éxito de la industria de los países en desarrollo de Asia en materia de competitividad internacional salta aún más a la vista si se compara esa situación con la de América Latina. La base de datos de la Naciones Unidas sobre el comercio internacional de manufacturas (COMTRADE) en el período 19661989 muestra que la participación de los países en desarrollo en las exportaciones de bienes manufacturados en ese período pasó de menos de $13 \%$ a más de 19\%: en las EAIR y los cuatro países de la ASEAN en conjunto aumentó de menos de $4 \%$ a más de $12 \%$, en tanto que en América Latina disminuyó de $5 \%$ a $4 \%$. Si observamos las industrias relativamente más avanzadas en el aspecto tecnológico, como la de la maquinaria eléctrica y los equipos electrónicos (CIU 383), la maquinaria exceptuada la eléctrica (CIIU 382) y el equipo de transporte (CIU 384), la situación es aún más reveladora.

En el mismo período la participación de los países en desarrollo de Asia en las exportaciones totales de bienes manufacturados correspondientes al rubro 382 de la Clasificación Industrial Internacional Uniforme (CIIU) se disparó de menos de $2 \%$ hasta casi $21 \%$, mientras que América Latina no superó el $2 \%$. Esto confirma que el éxito de dichos países asiáticos en la industria electrónica ha sido espectacular (Ernst y O'Connor, 1992, y Mody, 1989). En la industria de la maquinaria exceptuada la eléctrica (CIU 382), la participación de las exportaciones de bienes manufacturados de esos países pasó de menos de $1 \%$ a $9 \%$, en tanto que la de América Latina solamente aumentó de menos de $1 \%$ a un poco más de $1 \%$. En la industria de equipo de transporte (CIIU 384), los países en desarrollo de Asia aumentaron su participación en las exportaciones totales desde menos de $1 \%$ a más de $4 \%$, mientras que la penetración de América Latina en el mercado no sobrepasó el $2 \%$ en 1989. Así, el desempeño de las exportaciones del Asia en desarrollo no sólo superó ampliamente el de América Latina, sino que to hizo precisamente en las industrias de mayor complejidad tecnológica, en las que las empresas transnacionales tienden a dominar en el contexto del nuevo orden industrial internacional.

Blomström (1990, pp. 2 y 5) ha señalado que las corrientes de inversión extranjera directa hacia el sector manufacturero de los países en desarrollo han guardado relación tradicionalmente con la índole de las políticas industriales y comerciales aplicadas por esos países. En ese sentido, puede decirse que América Latina prefirió inicialmente una estrategia orientada hacia adentro, que atrajo inversiones extranjeras (principalmente de los Estados Unidos y Europa) destinadas a actividades manufactureras de sustitución de importaciones que disfrutaban de protección, y que no obstante sus esfuerzos por promover las exportaciones, nunca logró convencer realmente a las empresas transnacionales de que exportaran proporciones importantes de su producción local. Las economías recién industrializadas de Asia, cuyo proceso de industrialización fue relativamente tardío, avanzaron visiblemente de una industrialización sustitutiva hacia políticas orientadas más al exterior, junto con hacer empleo sensato de zonas francas para el procesamiento de exportaciones, lo que llev6 a las empresas transnacionales (principalmente japonesas) a orientar sus operaciones más a la exportación. Kojima (1975) hasta llegó a sugerir que la inversión extranjera directa pre- 
sentó variantes tanto favorables como adversas al comercio. Más adelante, en la sección III, examinaremos las similitudes y diferencias en las operaciones de las empresas transnacionales del Japón y los Estados Unidos en ambas regiones.

Las corrientes de inversión extranjera directa hacia América Latina tuvieron un auge en el decenio de 1970 y la región pareció estar incorporándose gradualmente a la estructura productiva global, aunque en una visión retrospectiva se hace evidente que las corrientes de comercio de la región, y en especial sus exportaciones, no fueron a la par con la llegada de inversión extranjera directa. El proceso de industrialización sustitutivo, cuyo dinamismo dependía del mercado local, se tambaleó con la crisis de la deuda externa en los años ochenta. En cambio, en las economías de industrialización reciente de Asia, el sesgo exportador de su industrialización se adaptó bien, en los años sesenta y setenta a un comercio multilateral en expansión y a la creación de un sistema regional de abastecimiento por las empresas transnacionales del Japón, y en los ochenta al auge de las importaciones de los Estados Unidos y al aumento explosivo de la inversión extranjera directa intrarregional asociada primordialmente a la red china de ultramar. ${ }^{3}$ Así las corrientes de inversión extranjera directa hacia Asia tuvieron un incremento repentino en los arios ochenta (FMI, 1992, p. 172) y los países asiáticos de industrialización reciente se fueron incorporando a la estructura global de producción.

Como se ilustra en el cuadro 2, una de las características que comparten el comercio y la inversión extranjera directa es la de que los avances principales tuvieron lugar en la región asiática en general, y en

${ }^{3}$ The Economist, 1991, p. 11, y 1992, pp. 21-24; CET, 1991b; Whitmore y Hyun, 1989.

CUADRO 2

Economias de mercado: afluencia de inversión extranjera directa por áreas y periodos, 1970-1989

(Corrientes anuales medias en millones de dólares y porcentajes)

\begin{tabular}{|c|c|c|c|c|c|c|c|c|}
\hline & $1970-74$ & $1975-79$ & $1980-84$ & $1985-89$ & $1970-74$ & $1975-79$ & $1980-84$ & $1985-89$ \\
\hline $\begin{array}{l}\text { Todas las economías de } \\
\text { mercado }\end{array}$ & 14691 & 27534 & 52841 & 117047 & 100.0 & 100.0 & 100.0 & 100.0 \\
\hline a) Economías industriales & 12682 & 21022 & 37326 & 100081 & 86.3 & 76.3 & 74.8 & 81.4 \\
\hline $\begin{array}{l}\text { b) Economías en } \\
\text { desarrollo }\end{array}$ & 2009 & 6512 & 15515 & 16966 & 13.7 & 23,7 & 25.2 & 18.6 \\
\hline $\begin{array}{l}\text { i) Asia } \\
\text { Taiwán (incluida }\end{array}$ & 673 & 1422 & 4907 & 12449 & 4.6 & 5.2 & 9.3 & 10.6 \\
\hline China $^{\mathrm{a}}$ & $\ldots$ & $\ldots$ & 530 & 2487 & $\ldots$ & $\ldots$ & 1.0 & 2.1 \\
\hline República de Corea & 77 & 71 & 71 & 580 & 0.5 & 0.3 & 0.1 & 0.5 \\
\hline Hong Kong & $\ldots$ & $\ldots$ & 680 & 1650 & $\ldots$ & $\ldots$ & 1.4 & 1.4 \\
\hline Singapur & 213 & 390 & 1387 & 2690 & 1.4 & 1.4 & 2.6 & 2.3 \\
\hline Malasia & 210 & 442 & 1131 & 799 & 1.4 & 1.6 & 2.1 & 0.7 \\
\hline Tailandia & 83 & 64 & 285 & 732 & 0.6 & 0.2 & 0.5 & 0.6 \\
\hline Filipinas & 4 & 110 & 39 & 389 & 0.0 & 0.4 & 0.1 & 0.3 \\
\hline ii) América Latina & 1588 & 3574 & 5434 & 5655 & 10.8 & 13,0 & 10.3 & 4.8 \\
\hline Brasil & 852 & 1823 & 2100 & 1426 & 5.8 & 6.6 & 4.0 & 1.2 \\
\hline México & 413 & 790 & 1499 & 2178 & 2.8 & 2.9 & 2.8 & 1.9 \\
\hline Argentina & 10 & 120 & 439 & 730 & 0.1 & 0.4 & 0,8 & 0.6 \\
\hline Colombia & 34 & 72 & 398 & 559 & 0.2 & 0.3 & 0.8 & 0.5 \\
\hline Chile & -142 & 99 & 242 & 125 & -1.0 & 0.4 & 0.5 & 0.1 \\
\hline Venezuela & -140 & -64 & 120 & 81 & -1.0 & -0.2 & 0.2 & 0.1 \\
\hline iii) Africa & 537 & 918 & 1096 & 2602 & 3.7 & 3.3 & 2.1 & 2.2 \\
\hline iv) Oriente medio & -19 & 275 & 323 & 547 & $-0,1$ & 1.0 & 0.6 & 0.5 \\
\hline Turquía & 58 & 52 & 65 & 271 & 0.4 & 0.2 & 0.1 & 0.2 \\
\hline
\end{tabular}

Fuente: Fondo Monelario Internacional, (cinta magnética de la balanza de pagos). Estimaciones del Centro de las Naciones Unidas sobre Empresas Transnacionales (CET) para Taiwán/China y Hong Kong.

a Como estas cifras incluyen el total combinado Taiwán/China, no son comparables con las estadísticas comerciales. 
los países recién industrializados de Asia en particular. Sin embargo, en el caso de la inversión extranjera directa, no solamente los logros de Asia fueron superiores a los de América Latina, sino que la incorporación cada vez mayor de Asia coincidió con una marginalidad cada vez más acentuada de América Latina, especialmente a partir de 1985. Desde el punto de vista de la afluencia de inversión extranjera directa como porcentaje del total mundial, en 1970-1989 América Latina y los países en desarrollo de Asia intercambiaron posiciones. La marginalidad de los países en desarrollo ante las corrientes de inversión extranjera directa global se acentuó -su participación bajó de $25 \%$ a $19 \%$ en el decenio de $1980-$; sin embargo, Asia en realidad aument 6 su participación de $5 \%$ a $11 \%$ entre 1970 y 1989 y el incremento se concentró principalmente en los países recién industrializados. América Latina, por su lado, bajó su participación de $11 \%$ a menos de $5 \%$ en el mismo período, después de haber alcanzado un nivel máximo de 13\% en 1975-1979, y fue la región en desarrollo de más rápida marginalización.

Es evidente que Asia en desarrollo y América
Latina han tenido experiencias radicalmente distintas en relación con sus procesos de industrialización, la competitividad internacional de sus productos manufacturados y la índole de su incorporación al nuevo orden industrial internacional. La imagen de los ánsares en vuelo (flying wild geese) en oposición a los patos inmóviles (sitting ducks) es muy apropiada, porque la formación de los primeros sugiere orden y rumbo, y porque su movimiento los pone fuera del alcance de la mayoría de los depredadores - en este caso los cazadores-. El pato inmóvil, en cambio, es un blanco indefenso con escasas esperanzas de escapatoria.

Habiendo asociado la industria de Asia en desarrollo con la imagen de los ánsares en vuelo y la industria latinoamericana con la de los patos inmóviles, es necesario identificar los factores que explican esas caracterizaciones diferentes. A continuación, señalamos que el país de origen de la inversión extranjera directa (considerada también la fuente de la tecnología extranjera) y la forma de dicha inversión o transferencia tecnologica son elementos decisivos para explicar tales diferencias.

\section{III}

\section{Origen y forma de la inversión extranjera directa y de la tecnología y sus efectos en la competitividad internacional}

Ante todo debe tenerse en cuenta explícitamente, en cada caso, el país de origen de los principales inversionistas y proveedores extranjeros de tecnología foránea. Como no se cuenta con información detallada y comparable sobre las operaciones de las empresas transnacionales europeas como grupo, este análisis sólo considerará las actividades de las empresas transnacionales de los Estados Unidos y Japón.

\section{Características de las empresas transnacio- nales de los Estados Unidos en la Industria Latinoamericana}

Las empresas transnacionales estadounidenses (y europeas) han predominado en las corrientes de inversión extranjera directa y la transferencia de tecnología hacia América Latina, en tanto que las transnacio- nales japonesas han logrado recientemente un predominio en las economías asiáticas de industrialización reciente (CET, 1992 y en prensa). Habida cuenta de que las subsidiarias de las empresas transnacionales de los Estados Unidos fueron concebidas primordialmente para atender a las necesidades de sustitución de importaciones de las economías locales, o en menor grado, a la necesidad de esas mismas transnacionales de contar con materias primas procesadas, las exportaciones de productos manufacturados no eran un componente importante de esas operaciones. Si bien es cierto que las empresas transnacionales estadounidenses generaron una proporción creciente de las exportaciones manufactureras de América Latina, en general la propensión a exportar fue baja debido a la preferencia por las ventas locales, generalmente mucho más rentables, y a la ineficiencia relativa de las ope- 
raciones locales. Las empresas transnacionales estadounidenses dominaron amplias esferas del sector industrial latinoamericano (Newfarmer y Mueller, 1975), especialmente en los rubros de productos químicos y maquinaria, y la eficiencia limitada de sus operaciones, generalmente les impidió estimular de manera significativa la competitividad de las empresas nacionales, en especial desde una perspectiva exportadora (Jenkins, 1990, p. 218; Blomström, 1990).

Aunque los gobiernos de América Latina tendieron a ceder las industrias tecnológicamente más complejas a las empresas transnacionales (en particular la de maquinaria y productos químicos), en la creencia de que estas aportarían la tecnología necesaria, obligaron a menudo a las transnacionales a asociarse con empresas locales en determinadas actividades (es decir, la industria petroquímica, de autopartes, de equipos de computación, etc.). A partir de la crisis de la deuda externa en los años ochenta, la transformación de las industrias sustitutivas de importaciones en industrias de exportación se ha convertido en una necesidad urgente para las empresas transnacionales estadounidenses que operan en América Latina. Aún no se conoce bien cuánto han logrado esas empresas, pero se sabe que las políticas de liberalización del comercio han sido menos dinámicas de lo previsto en provocar el ajuste estructural a nivel empresarial (Papageorgiu, Choksi y Michaely, 1990; Ten Kate, 1992)

\section{Características de las empresas transnacio- nales japonesas en la industrla de Asia en desarrollo}

El impacto de las empresas transnacionales del Japón sobre el sector manufacturero de los países asiáticos de industrialización reciente parece haber sido muy distinto. Las transnacionales japonesas al parecer establecieron sus metas para la inversión extranjera y la transferencia tecnológica en función de factores vinculados con la competitividad internacional y no sólo con el tamaño de los mercados nacionales. En una proporción significativa, lo que hicieron las transnacionales del Japón fue transferir al extranjero actividades japonesas que habían perdido competitividad ante regiones de salarios más bajos, y establecer centros de abastecimiento de componentes de bajo costo para industrias internacionales de integración vertical. Habida cuenta del tamaño reducido de la mayoría de los mercados locales de los países en desarrollo de Asia, el sesgo exportador era fundamental para el proceso decisorio en materia de inversiones y transfe- rencia de tecnología. Esta transición también fue estimulada mediante zonas francas para el procesamiento de las exportaciones.

Las operaciones cuyo capital pertenecía mayoritariamente a empresas transnacionales japonesas ordinariamente generaron una cantidad considerable de actividades de subcontratación para las empresas locales en las zonas receptoras (Sato, 1986; Minato, 1986). Cuando el vender en el mercado nacional se hizo interesante para estos inversionistas japoneses, a menudo proliferaron las empresas con participación accionaria de los asociados locales. La inversión extranjera directa del Japón contribuyó mucho a reubicar la producción dentro de la región asiática en respuesta a variaciones en las ventajas competitivas (Naciones Unidas, 1991, p. 86); sin embargo, lo más importante era que la competitividad internacional de esas economías estaba más bien a cargo de compañías nacionales (CET, 1992; The Economist, 1991, p. 11), sobre todo de compañías locales contratadas como proveedoras de las empresas transnacionales del Japón. Cuando estas últimas perdieron sus ventajas competitivas, las economías asiáticas de industrialización reciente de Asia pudieron satisfacer las exigencias de costo y calidad de las transnacionales japonesas y ello constituyó un fuerte estímulo para consolidar un proceso sólido de industrialización exportadora. Detrás de los países asiáticos de industrialización reciente aguardaban su oportunidad los cuatro países de la ASEAN, no sólo en industrias con uso intensivo de mano de obra, sino también en aquéllas cuya mejora tecnológica aumentaba su competitividad internacional (véase por ejemplo Dahlman y Brimble, 1990).

En vez de comparar las operaciones de las transnacionales de los Estados Unidos en América Latina con las actividades de las transnacionales japonesas en Asia en general, aquí se ha preferido enfocar el análisis sobre las industrias tecnológicamente más adelantadas (maquinaria y equipo de transporte) de las empresas transnacionales de los Estados Unidos y del Japón, especialmente las que operan en América Latina y Asia. Se ha estimado que de esta manera se ofrecería una visión más clara de la índole de la competencia internacional en la frontera teconológica, por cuanto suponía la participación de países en desarrollo.

\section{La situación en las industrias de mayor com- plejidad tecnológica}

El cuadro 3 retrata los cambios ocurridos en el decenio 
de 1980 en las actividades de mayor complejidad tecnológica del sector manufacturero. Puede observarse que mientras el monto de la inversión extranjera directa de los Estados Unidos en este sector, en general, y en las industrias de maquinaria y de equipo de transporte en particular, era mayor que la del Japón, (77000 millones de dólares contra 20000 millones) las industrias más modernas en el plano tecnológico tenían una participación similar (alrededor de $38 \%$ del total para el sector manufacturero) en términos de la estructura de la inversión extranjera directa. Mien- tras la inversión extranjera directa de los Estados Unidos tendía a centrarse más bien en el sector de la maquinaria en general (13.4\%), la del Japón apuntaba más a los equipos eléctricos (14.4\%). Una concentración semejante (en torno a 14\%) se hallo en la industria del equipo de transporte. Al llegar a 1989 se habían producido grandes cambios: la inversión extranjera directa de los Estados Unidos (156000 millones de dólares) aún era muy superior a la del Japón (66000 millones de dólares); sin embargo, esta última crecía con mayor rapidez.

CUADRO 3

Estados Unidos y Japón: inversión extranjera directa (IED) en el sector manufacturero: comparación de su crecimiento y la distribución regional, 1982-1989

\begin{tabular}{|c|c|c|c|c|c|c|c|c|c|c|c|c|}
\hline & \multicolumn{2}{|c|}{$\begin{array}{c}\text { Comunidad } \\
\text { Europea }\end{array}$} & \multicolumn{2}{|c|}{$\begin{array}{l}\text { América } \\
\text { del Norte a }\end{array}$} & \multicolumn{2}{|c|}{ Japónb } & \multicolumn{2}{|c|}{$\begin{array}{l}\text { América } \\
\text { Latina }\end{array}$} & \multicolumn{2}{|c|}{$\begin{array}{c}\text { Asia en } \\
\text { desarrollo }\end{array}$} & \multicolumn{2}{|c|}{$\begin{array}{c}\text { Todos los } \\
\text { países }\end{array}$} \\
\hline & 1982 & 1989 & 1982 & 1989 & 1982 & 1989 & 1982 & 1989 & 1982 & 1989 & 1982 & 1989 \\
\hline \multicolumn{13}{|l|}{ IED de EE.UU. (miles de } \\
\hline Maquinaria general (no & & & & & & & & & & & & \\
\hline eléctrica) & 7.4 & 16.4 & 1.9 & 3.3 & c & 2.6 & 1.7 & 2.8 & 0.2 & 0.8 & 13.4 & 27.1 \\
\hline Equipo eléctrico & 2.5 & 4.1 & 1.3 & 2.2 & 0.1 & 1.2 & 1.0 & 1.1 & 0.9 & 2.7 & 6.7 & 11.9 \\
\hline Equipo de transporte & 3.4 & 9.2 & 3.8 & 7.7 & $\ldots$ & 2.3 & 1.7 & 3.2 & 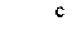 & 0.3 & 10.1 & 23.5 \\
\hline IEU de EE.LU. (porcentaje) & 43.4 & 48.1 & 23.9 & 20.7 & 2.3 & 6.4 & 18.0 & 13.7 & 2.7 & 4.3 & 100 & 100 \\
\hline \multicolumn{13}{|l|}{ Maquinaria general (no } \\
\hline eléctrica) & 9.6 & 10.5 & 2.5 & 2.1 & : & 1.7 & 2.2 & 1.8 & 0.3 & 0.1 & 17.4 & 17.4 \\
\hline Equipo eléctrico & 3.3 & 2.6 & 1.2 & 1.4 & 0.1 & 0.8 & 1.3 & 0.7 & 1.1 & 1.8 & 8.8 & 7.6 \\
\hline Equipo de transporte & 4.4 & 5.9 & 5.0 & 4.9 & $\ldots$ & 1.5 & 2.2 & 1.4 & c & 0.2 & 13.2 & 15.1 \\
\hline \multicolumn{13}{|l|}{ IED del Japón b (miles de } \\
\hline millones de dólares) & 1.4 & 7.9 & 5.2 & $\mathbf{3 3 . 5}$ & - & - & 3.9 & 5.6 & 6.5 & 15.6 & 19.5 & 66.1 \\
\hline \multicolumn{13}{|l|}{ Maquinaria general (no } \\
\hline eléctrica) & 0.2 & 1.8 & 0.5 & 4.0 & - & - & 0.3 & 0.4 & 0.4 & 1.6 & 1.4 & 7.9 \\
\hline Equipo eléctrico & 0.3 & 2.0 & 1.5 & 8.7 & - & - & 0.3 & 0.5 & 0.7 & 3.3 & 2.8 & 14.7 \\
\hline Equipo de transporte & 0.2 & 1.3 & 0.8 & 4.5 & - & - & 0.6 & 1.1 & 0.5 & 1.3 & 2,9 & 9.0 \\
\hline IED del Japón (porcentaje) & 7.2 & 12.0 & 26.7 & 50.7 & - & $\therefore$ & 20.0 & 8.5 & $\mathbf{3 3 . 3}$ & 23.6 & 100 & 100 \\
\hline \multicolumn{13}{|l|}{ Maquinaria general (no } \\
\hline eléctrica) & 1.0 & 2.7 & 2,6 & 6.1 & - & - & 1.5 & 0.6 & 2.1 & 2.4 & 7.2 & 12.0 \\
\hline Equipo eléctrico & 1.5 & 3.0 & 7.7 & 13.2 & - & - & 1.5 & 0.8 & 3.6 & 5.0 & 14.4 & 22,2 \\
\hline Equipo de transporte & 1.0 & 2.0 & 4.1 & 6.8 & - & - & 3.0 & 1.7 & 2.6 & 2.0 & 14.9 & 13.6 \\
\hline
\end{tabular}

Fuente: La información de los Estados Unidos está tomada de Estados Unidos, Departamento de Comercio, US Direct Investment Abroad: 1982 Benchmark Survey Data, Washington, D.C., diciembre de 1985, y Survey of Current Business, vol. 70, No 8, Washington, D.C., agosto de 1990. La información del Japón proviene de Kerai Koho Center, Japan 1992: An Iniernational Comparison, Tokio, 1992, y Japan 1984: An International Comparison, Tokio.

"Como región de destino de la inversión extranjera directa (IED) de los Estados Unidos, América del Norte significa Canadá.

b Las cifras del Japón corresponden a marzo de 1984 y marzo de 1990.

c Información no revelada.

La estructura de la inversión extranjera directa de los Estados Unidos no se modificó de manera importante en los años ochenta (las corrientes de inversión eran pequeñas en comparación con el enorme monto acumulado). En cambio, la de Japón se espe- cializó aceleradamente en la maquinaria y en el equipo de transporte y su ritmo de crecimiento fue muy superior al de la inversión extranjera directa de los Estados Unidos. En otras palabras, la inversión extranjera directa del Japón durante este período mostró mucho 
mayor dinamismo en su expansión (con el espaldarazo, después de 1985 , de la fuerte revalorización del yen) y en su especialización en sectores tecnológicamente complejos (los que aumentaron de $36.5 \%$ a $48 \%$ su participación en el monto total de la inversión extranjera directa en el sector manufacturero).

Interesa especialmente la orientación regional de la inversión extranjera directa efectuada por los Estados Unidos y Japón durante los años ochenta en estas mismas industrias. En el cuadro 3 puede apreciarse que el monto acumulado de la de los Estados Unidos, que se había centrado históricamente en la Comunidad Europea (43.4\% en 1982), Canadá (24\%) y América Latina (18\%), se había modificado un tanto al llegar a 1989. Acusaron incrementos relativos la Comunidad Europea (a 48\%), Japón (de $2.4 \%$ a $6.4 \%$ ) y los países en desarrollo de Asia (de $2.7 \%$ a $4.3 \%$ ), mientras que Canadá registró una disminución relativamente pequeña y América Latina un fuerte descenso (de $18 \%$ a $13.7 \%$ ). La inversion extranjera directa de los Estados Unidos seguía centrada en la Comunidad Eutopea y Canadá, pero la región asiática (Japón y los países en desarrollo de Asia) al parecer estaba a punto de desplazar a América Latina como destino de la inversión extranjera directa de las empresas transnacionales estadounidenses que operaban en la industria manufacturera. En lo que toca a la especialización industrial en los sectores de la maquinaria y el equipo de transporte, los mayores cambios tuvieron que ver con la nueva inversión extranjera directa en el sector de equipo de transporte en Europa y Japón y en la industria de maquinaria eléctrica y equipos electrónicos en los países en desarrollo de Asia. Aunque se trataba de corrientes relativamente pequeñas frente al considerable monto acumulado de la inversión extranjera directa en el caso de las empresas transnacionales de los Estados Unidos, en los años ochenta se observaron algunos cambios en la distribución geográfica de dicha inversión.

Las empresas transnacionales del Japón mostraron mucho mayor dinamismo en su inversión extranjera directa en el sector manufacturero durante el período 1983-1989, la que se centro casi exclusivamente en el mercado norteamericano: allí aumentó de $27 \%$ a $51 \%$ del total de la inversión extranjera directa del Japón en el sector manufacturero. Los países en desarrollo de Asia, que anteriormente habían sido el centro de atención de la incipiente red de inversión extranjera directa y habían absorbido la tercera parte del total destinado a la industria manufacturera, disminuyeron su partici- pación relativa a $24 \%$. América Latina, por su parte, vio descender vertiginosamente su participación en la inversión extranjera directa, de $20 \%$ a $8.5 \%$. Aparte la enorme expansión del mercado norteamericano, sólo la Comunidad Europea exhibió un incremento relativo importante (de $7 \%$ a $12 \%$ ). En cuanto a la especialización en las áreas de maquinaria y de equipo de transporte, los mayores incrementos se registraron en la industria de maquinaria eléctrica y equipo electrónico en América del Norte (de $7.7 \%$ a $13.2 \%$ ), los países en desarrollo de Asia (de $3.6 \%$ a $5 \%$ ) y la Comunidad Europea (de $1.5 \%$ a $3 \%$ ); el sector de la maquinaria no eléctrica en América del Norte (de $2.6 \%$ a $6.1 \%$ ) y Europa (de $1 \%$ a $2.7 \%$ ), y la industria de equipo de transporte en América del Norte (de $4.1 \%$ a $6.8 \%$ ) y la Comunidad Europea (de $1 \%$ a 2\%). Así, la inversión extranjera directa del Japón en el sector manufacturero fue mucho más dinámica que la de los Estados Unidos, y junto con especializarse en actividades tecnológicamente más complejas, se orientó cada vez más a los principales mercados de la Tríada durante los años ochenta.

Un rasgo común a la especialización regional de la inversión extranjera directa de los Estados Unidos y de Japón en 1982-1989 fue el aumento de la marginalidad de América Latina, unido al desplazamiento gradual de esta región por los países en desarrollo de Asia. Esto ocurrió especialmente en el sector de la maquinaria eléctrica y los equipos electrónicos. En el cuadro 4 figura información más detallada acerca de los aspectos internacionales de las filiales de empresas transnacionales estadounidenses y japonesas que operan en estas regiones y su importancia en las redes de empresas transnacionales.

Pero antes de analizar dicha información cabe señalar que aunque actualmente se dispone de datos relativamente confiables y congruentes acerca de la índole y estructura de las actividades de las empresas transnacionales de los Estados Unidos y Japón, la información estadística dista mucho de ser completa. ${ }^{4}$ Las autoridades nacionales recopilan la información con diversos propósitos. La información más detallada de los Estados Unidos se refiere solamente a filiales con capital extranjero mayoritario, mientras que la del Japón abarca a todos los asociados res-

\footnotetext{
${ }^{4}$ Entre otros análisis de los problemas relacionados con datos sobre la inversión extranjera directa, se puede consultar oCDE, 1987; Stekler y Stevens, 1991 ; Estados Unidos, Departamento de Comercio, 1988, y Patterson, 1990.
} 
pecto de los cuales la casa matriz o sus filiales poseen más de $10 \%$ del capital accionario. ${ }^{5}$ La red de empresas transnacionales del Japón es más propensa que la de los Estados Unidos a las coinversiones, es decir, a la participación minoritaria en el capital de la empresa local (Whitmore y Hyun, 1989). Esto, sin embargo, hace que la participación minoritaria transnacionales de los Estados Unidos en sectores importantes, como la industria automovilística del Japón, no figure en los cuadros de ventas. Asimismo, la cobertura del estudio japonés no es tan completa como la del correspondiente a los Estados Unidos. En la versión de 1989 del estudio japonés se incorporó menos del $65 \%$ de las ventas globales de productos manufacturados, siendo la cifra particularmente baja respecto de las empresas transnacionales productoras de equipo de transporte $(42 \%$ de las ventas). Por lo demás, los datos sobre los Estados Unidos se refieren sólo a las importaciones desde este país, mientras que las cifras sobre Japón suministran información acerca de importaciones procedentes del Japón y terceros países. Pese a los problemas estadísticos implícitos, los "estudios de referencia" del Departamento de Comercio de los Estados Unidos y del Ministerio de Industria y Comercio Internacional del Japón son las fuentes más completas de información comparativa sobre este tema.

Respecto del sector manufacturero en su conjunto, la información que figura en el cuadro 4 indica, ante todo, que América Latina nunca fue un elemento importante en las operaciones de las empresas transnacionales de Japón (solo 8\% de las ventas locales y exportaciones en 1983), en tanto que los países en desarrollo de Asia sí lo fueron con $35 \%$ de las ventas locales, más de la mitad de todas las exportaciones y casi $40 \%$ de todas las importaciones). En segundo lugar, durante el decenio de 1980 América Latina se tornó aún menos importante para las transnacionales japonesas (3\% de todas la ventas); los países en desarrollo de Asia, en tanto, conservaban una participación muy importante $(29 \%$ de todas

\footnotetext{
${ }^{5}$ Es útil distinguir tres categorías de empresas locales vinculadas a las empresas transnacionales, según la participación de capital extranjero en su capital social: i) con $100 \%$ de capital extranjero, conocidas como subsidiarias; ij) con 51 a $99 \%$ de capital extranjero, calificadas como filiales con capital mayoritariamente extranjero; y iii) con 10 (o 25) a $50 \%$ de capital extranjero, consideradas asociadas ofiliales con capital mayoritariamente local. Los diferentes niveles de participación del capital extranjero tienen importantes implicaciones respecto al control de las empresas locales. A veces se juntan las dos primeras categorías en una categoría de empresas controladas por sus socios extranjeros.
}

la ventas, más de la mitad de las exportaciones y la cuarta parte de todas las importaciones en 1989), pese a que en ese decenio las corrientes de inversión japonesas se concentraron cada vez más en el mercado norteamericano. En tercer lugar, de estas cifras se infiere que las empresas transnacionales del Japón crearon sistemas de abastecimiento y plataformas de exportación regionales en el Asia en desarrollo. El comercio exterior desempeñó un papel fundamental en estas operaciones, no sólo para el comercio con Japón sino también para las exportaciones hacia terceros países y las importaciones procedentes de éstos. Los países en desarrollo de Asia fueron un núcleo de la expansión internacional de las empresas transnacionales japonesas. América Latina desempeñó un papel marginal y cada vez menor.

En cuanto a las operaciones de las filiales con capital mayoritario estadounidense de empresas transnacionales de los Estados Unidos en el sector manufacturero, puede decirse que tanto América Latina como los países en desarrollo de Asia han desempeffado en ellas un papel relativamente secundario, aunque el de América Latina ha sido históricamente mucho más importante. En 1977 el valor de las ventas de su red latinoamericana era cinco veces mayor que el de aquéllas del Asia en desarrollo, y representaba el $16 \%$ de todas las ventas locales (pero sólo $4 \%$ de todas las exportaciones) de bienes manufacturados. En 1977 1982 se acentuó la importancia relativa de América Latina y la participación de las empresas transnacionales estadounidenses en las ventas locales en la región, que alcanzaron al $19 \%$ de todas las ventas de artículos manufacturados (pero sólo al 5\% de las exportaciones totales). En 1982-1989 aumentó la marginalidad de las filiales latinoamericanas con capital mayoritario estadounidense las transnacionales estadounidenses (las que bajaron a sólo $12 \%$ de todas la ventas locales); sin embargo, se produjo un cambio en la naturaleza de esas operaciones, que se orientaron algo más a la exportación (contribuyeron con $6 \%$ de todas las exportaciones de bienes manufacturados) y comenzaron a convertirse en abastecedoras de las transnacionales estadounidenses (suministraron $9 \%$ de todas las exportaciones manufactureras de estas empresas al mercado de los Estados Unidos), aun cuando disminuyeron las exportaciones a terceros países. Pese a los cambios emprendidos, las filiales latinoamericanas con capital mayoritario estadounidense de las transnacionales de los Estados Unidos no llegaron a constituir una red importante de abastecimiento ni una plataforma de exportación notable. 
Fillales de empresas transnacionales Japonesas y estadounidenses en el sector manufacturero: análisis comparativo de sus aspectos internacionales, por regiones, 1977, 1982 y 1989

\begin{tabular}{|c|c|c|c|c|c|c|c|c|c|c|}
\hline & \multicolumn{4}{|c|}{ Filiales japonesas } & \multicolumn{6}{|c|}{ Filiales extranjeras con capital mayoritariamente estadounidense } \\
\hline & \multicolumn{2}{|c|}{1982} & \multicolumn{2}{|c|}{1989} & \multicolumn{2}{|c|}{1977} & \multicolumn{2}{|c|}{1982} & \multicolumn{2}{|c|}{1989} \\
\hline & $\begin{array}{l}\text { Millones } \\
\text { de dls. }\end{array}$ & $\begin{array}{l}\% \text { ind. } \\
\text { total }\end{array}$ & $\begin{array}{l}\text { Millones } \\
\text { de dls. }\end{array}$ & $\begin{array}{l}\% \text { ind } \\
\text { total }\end{array}$ & $\begin{array}{l}\text { Millones } \\
\text { de dls. }\end{array}$ & $\begin{array}{l}\% \text { ind. } \\
\text { total }\end{array}$ & $\begin{array}{l}\text { Millones } \\
\text { de dls. }\end{array}$ & $\begin{array}{l}\% \text { ind. } \\
\text { total }\end{array}$ & $\begin{array}{l}\text { Millones } \\
\text { de dls. }\end{array}$ & $\begin{array}{l}\% \text { ind. } \\
\text { total }\end{array}$ \\
\hline \multicolumn{11}{|c|}{ A. Todas las manufacturas } \\
\hline América Latina (total) & 2011 & 8 & 3081 & 3 & 24217 & 12 & 39506 & 15 & 47539 & 9 \\
\hline 1.Ventas locales & 1480 & 8 & 2154 & 3 & 21876 & 16 & 34814 & 19 & 37363 & 12 \\
\hline 2.Exportaciones & 531 & 8 & 927 & 4 & 2341 & 4 & 4692 & 5 & 10176 & 6 \\
\hline -al país de origen & $(229)$ & (8) & (335) & (4) & $(874)$ & (5) & $(1855)$ & (7) & $(6412)$ & (9) \\
\hline -a otros países & $(302)$ & (8) & (592) & (5) & (1 467) & (3) & (2 837) & (4) & (3 764) & (3) \\
\hline 3.Importaciones & 203 & 3 & 295 & 1 & & & & & & \\
\hline -del país de origen & (187) & (3) & $(119)$ & $(\ldots)$ & $(2644)$ & (11) & $(4379)$ & (13) & $(8577)$ & (13) \\
\hline -de otros países & (16) & (1) & $(176)$ & (3) & & & & & & \\
\hline Asia en desarrollo (total) & 9920 & 40 & 29533 & 29 & 5125 & 3 & 9933 & 4 & 24647 & 5 \\
\hline 1. Ventas locales & 6585 & 35 & 18877 & 23 & 2204 & 2 & 2550 & 1 & 10787 & 3 \\
\hline 2. Exportaciones & 3335 & 51 & 10654 & 51 & 2921 & 5 & it & $\mathrm{a}$ & 13861 & 8 \\
\hline -al país de origen & (1 107) & (39) & (4669) & (57) & a & a & $(4060)$ & $(15)$ & $(8535)$ & (13) \\
\hline - atros países & $(2227)$ & $(61)$ & (5987) & (47) & a & a & (1 894) & (3) & $(5326)$ & (5) \\
\hline 3. Importaciones & 2655 & 38 & 8246 & 25 & & & & & & \\
\hline -del país de origen & (1 845) & (31) & (6 381) & (23) & (935) & (4) & $(2771)$ & (8) & $(4524)$ & 7 \\
\hline -de otros países & (1 810) & (70) & $(1865)$ & (36) & & & & & & \\
\hline \multicolumn{11}{|l|}{ B. Maquinaria no eléctrica } \\
\hline América Latina (total) & 84 & 17 & 241 & 4 & 1899 & 7 & 3315 & 8 & 5768 & 6 \\
\hline 1. Ventas locales & 70 & 18 & 230 & 5 & 1649 & 9 & 1705 & 11 & 4102 & 7 \\
\hline 2. Exportaciones & 14 & 13 & 10 & 1 & 250 & 2 & $61 !$ & 4 & 1666 & 4 \\
\hline -al país de origen & (9) & (16) & (1) & $(\ldots)$ & (28) & (2) & (104) & (3) & $(819)$ & (4) \\
\hline a otros países & (4) & (8) & $(10)$ & (1) & (222) & (2) & $(507)$ & (4) & $(847)$ & (4) \\
\hline 3. Importaciones & 14 & 11 & 14 & I & & & & & & \\
\hline -del país de origen & (14) & (11) & (6) & $(\ldots)$ & (195) & (6) & $(354)$ & (7) & (784) & (7) \\
\hline -de otros países & $(\ldots)$ & $(\ldots)$ & (8) & (6) & & & & & & \\
\hline Asia en desarrollo (total) & 311 & 63 & 1396 & 25 & 243 & 1 & 796 & 2 & a & it \\
\hline 1. Ventas locales & 224 & 59 & 794 & 19 & 71 & ... & : & a & a & a \\
\hline 2. Exportaciones & 87 & 81 & 602 & 42 & 172 & 2 & a & a & a & a \\
\hline -al país de origent & (47) & (82) & (254) & (88) & (99) & (8) & (312) & (10) & a & a \\
\hline -a otros países & $(40)$ & (78) & (348) & (30) & (73) & (1) & (24) & (2) & a & a \\
\hline 3. Importaciones & 82 & 31 & 396 & 20 & & & & & & \\
\hline -del país de origen & (81) & (65) & $(363)$ & (20) & (51) & (2) & $(187)$ & (4) & $(907)$ & (8) \\
\hline -de otros países & (1) & $(\ldots)$ & (33) & (26) & & & & & & \\
\hline \multicolumn{11}{|c|}{ C. Maquinaria eléctrica y equipo electrónico } \\
\hline América Latina (total) & 203 & 3 & 812 & 2 & 1991 & 11 & 2674 & 11 & 3598 & 10 \\
\hline 1. Ventas locales & 200 & 4 & 771 & 3 & 1649 & 13 & 2065 & 14 & 2219 & 10 \\
\hline 2. Exportaciones & 3 & ... & 406 & 4 & $34 \mathrm{l}$ & 5 & 608 & 6 & 1379 & 9 \\
\hline -al país de origen & $(\ldots)$ & $(\ldots)$ & $(\ldots)$ & $(\ldots)$ & (260) & (12) & (507) & (11) & (1 272) & (18) \\
\hline -a otros países & (3) & $(\ldots)$ & $(400)$ & (7) & (81) & (2) & (101) & (2) & $(107)$ & (l) \\
\hline 3. Importaciones & 34 & 1 & 10 & 1 & & & & & & \\
\hline -del país de origen & (34) & (1) & (68) & (1) & (348) & (15) & (927) & (20) & (2054) & (27) \\
\hline -de otros países & $(\ldots)$ & $(\ldots)$ & (33) & (1) & & & & & & \\
\hline Asia en desarrollo (total) & 2308 & 32 & 10390 & 27 & 2306 & 12 & 5099 & 20 & 9217 & 25 \\
\hline 1. Ventas locales & 846 & 15 & 3888 & 14 & a & $\mathrm{a}$ & 621 & 4 & 2958 & 13 \\
\hline 2. Exportaciones & 1462 & 86 & 6502 & 72 & a & a & 4478 & 44 & 6259 & 41 \\
\hline -al país de origen & (519) & (86) & $(2798)$ & (89) & a & a & (3 325) & $(72)$ & $(3847)$ & (55) \\
\hline -a otros países & (943) & (86) & (3 704) & (63) & : & a & $(1153)$ & $(20)$ & $(2412)$ & $(29)$ \\
\hline 3. Importaciones & 642 & 21 & 3120 & 20 & & & & & & \\
\hline -de] país de origen & $(537)$ & (18) & $(2412)$ & (19) & (699) & (29) & $(2026)$ & (43) & $(2767)$ & (36) \\
\hline -de otros países & (104) & (74) & $(707)$ & (26) & & & & & & \\
\hline
\end{tabular}




\begin{tabular}{|c|c|c|c|c|c|c|c|c|c|c|}
\hline & \multicolumn{4}{|c|}{ Filiales japonesas } & \multicolumn{6}{|c|}{ Filiales extranjeras con capital mayoritariamente estadounidenso } \\
\hline & \multicolumn{2}{|c|}{1982} & \multicolumn{2}{|c|}{1989} & \multicolumn{2}{|c|}{1977} & \multicolumn{2}{|c|}{1982} & \multicolumn{2}{|c|}{1989} \\
\hline & $\begin{array}{l}\text { Millones } \\
\text { de dls. }\end{array}$ & $\begin{array}{l}\% \text { ind. } \\
\text { total }\end{array}$ & $\begin{array}{l}\text { Millones } \\
\text { de dls. }\end{array}$ & $\begin{array}{r}\% \text { ind. } \\
\text { total }\end{array}$ & $\begin{array}{l}\text { Millones } \\
\text { de dts. }\end{array}$ & $\begin{array}{l}\% \text { ind. } \\
\text { total }\end{array}$ & $\begin{array}{l}\text { Millones } \\
\text { de dls. }\end{array}$ & $\begin{array}{r}\% \text { ind. } \\
\text { total }\end{array}$ & $\begin{array}{l}\text { Millones } \\
\text { de dls. }\end{array}$ & $\begin{array}{r}\% \text { ind. } \\
\text { total }\end{array}$ \\
\hline \multicolumn{11}{|l|}{ D. Equipo de transporte } \\
\hline América Latina (total) & 574 & 11 & 201 & 1 & 5249 & 11 & 7558 & 13 & 9929 & 9 \\
\hline 1. Ventas locales & 546 & 12 & 191 & 1 & 4867 & 16 & 6887 & 21 & 6677 & 11 \\
\hline 2. Exportaciones & 531 & 8 & 9 & $\ldots$ & 382 & 2 & 671 & 3 & 2839 & 6 \\
\hline -al país de origen & (229) & (4) & $(-)$ & $(-)$ & a & a & $(432)$ & (4) & (413) & (10) \\
\hline -a otros países & (302) & (I1) & (9) & $(\ldots)$ & a & a & (239) & (2) & $(3565)$ & (2) \\
\hline 3. Importaciones & 111 & 8 & 20 & 1 & & & & & & \\
\hline -del país de origen & (110) & (9) & (20) & (...) & $(2644)$ & (11) & (4 379) & (13) & $(8577)$ & (13) \\
\hline -de otros países & (I) & (2) & $(\ldots)$ & (3) & & & & & & \\
\hline Asia en desartollo (total) & 1479 & 30 & 6008 & 28 & a & a & a & n & 1727 & 2 \\
\hline 1. Ventas locales & 1282 & 28 & 5534 & 28 & a & a & $\mathrm{s}$ & a & 1608 & 3 \\
\hline 2. Exportaciones & 198 & 56 & 474 & 27 & a & a & 234 & 1 & 119 & $\cdots$ \\
\hline -al país de origen & (82) & (57) & (97) & (17) & a & a & (155) & (1) & (69) & $\ldots$ \\
\hline -a otros países & $(116)$ & (55) & (377) & (32) & $\mathrm{a}$ & a & (79) & (i) & 50 & $\ldots$ \\
\hline 3. Importaciones & 362 & 28 & 1554 & 18 & & & & & & \\
\hline -del país de origen & (328) & (26) & (1 537) & (18) & (11) & (1) & (57) & (...) & (95) & $(\ldots)$ \\
\hline -de otros países & (34) & $(68)$ & (17) & (25) & & & & & & \\
\hline
\end{tabular}

Fuente: Estados Unidos, Departamento de Comercio, US Direct Investment Abroad: 1977 Benchmark Survey, Washington, D.C., abril de 1981, US Direct Investment Abroad: 1982 Benchmark Survey, Washington, D.C., diciembre de 1985, y US Direct Investment Abroad: 1989 Benchmark Survey, Washington, D.C, octubre de 1991. Japón, Ministerio de Industria y Comercio Internacional, Benchmark Survey on Japanese Companies Foreign Activities: Compendium on Foreign Activity Data, Tokio, 1986, y Benchmark Survey on Japanese Companies Foreign Activities: Compendium on Foreign Activity Data, Tokio, 1991.

a Información no revelada.

Las operaciones de las transnacionales estadounidenses en los países en desarrollo de Asia en 1977 tuvieron una importancia marginal, ya que dieron lugar solamente al $2 \%$ de las ventas locales y al $5 \%$ de las exportaciones totales de bienes manufacturados por las filiales de los Estados Unidos en ese año. Aun así, las exportaciones de estas transnacionales estadounidenses en los países en desarrollo de Asia superaban ya las de sus operaciones en América Latina. En 1989, sus ventas globales habían casi quintuplicado su valor (equivalente entonces a cerca de la mitad de las operaciones en América Latina) y las ventas para la exportación habían subido bruscamente a casi $8 \%$ de todas las exportaciones de estas firmas y a $13 \%$ de sus exportaciones totales hacia los Estados Unidos. De modo que aunque las operaciones de las filiales con capital mayoritariamente estadounidense de empresas transnacionales de ese país en América Latina siguieron siendo importantes desde el punto de vista de las ventas totales, perdieron relevancia en la estrategia $y$ en la estructura productiva globales de las empresas transnacionales. Las operaciones en los países en desarrollo de Asia adquirieron mayor importancia, especialmente en lo tocante a las exportaciones, sobre todo al mercado norteamericano. Los países asiáticos en desarrollo comenzaban a convertirse en centros de abastecimiento para las empresas transnacionales de los Estados Unidos. Como se verá más adelante, la actividad principal de esas empresas en Asia en desarrollo se relacionó con la industria sumamente dinámica de la maquinaria eléctrica y los equipos electrónicos.

En otras palabras, las operaciones en América Latina adquirieron cada vez mayor importancia para las transnacionales estadounidenses mientras esas empresas consideraron las ventas locales como su principal actividad; pero perdieron importancia relativa a medida que las actividades de exportación iban siendo más valoradas por esas empresas, aunque éstas hicieron algunos ajustes en 1989 para acrecentar sus actividades de exportación en América Latina.

En los países en desarrollo de Asia, las empresas transnacionales estadounidenses enfocaron claramente sus operaciones hacia las actividades de abastecimiento y comercio de maquinaria eléctrica y equipo electrónico.

Se ve así que las transnacionales japonesas han centrado mucho más su atención en los países en desarrollo de Asia y que sus operaciones suponen altos niveles de comercio exterior, lo que concuerda 
con la visión de que su finalidad primordial apunta al ensamblaje de componentes y a constituir fuentes de abastecimiento. Las transnacionales de los Estados Unidos, que en general dependen menos de las instalaciones productivas de los países en desarrollo (en relación con las de los países desarrollados), habían tendido a concentrar estas actividades en América Latina y básicamente servían al mercado local. Esta diferencia entre las operaciones manufactureras de las empresas transnacionales del Japón y de los Estados Unidos en las regiones en desarrollo comenzó a diluirse en los años ochenta, a medida que las actividades de las transnacionales estadounidenses en América Latina perdieron importancia en el contexto global de la estrategia de las transnacionales, y a medida que las actividades de esas transnacionales en los países en desarrollo de Asia adquirieron mayor empuje. Esto resulta evidente si se analiza la situación de las industrias tecnológicamente más complejas (cuadro 4).

Cabe subrayar que las operaciones de las empresas transnacionales del Japón en los sectores de la maquinaria y el equipo de transporte de América Latina carecen de importancia global, aun si se tiene en cuenta que hay subestimaciones evidentes en los informes del sector del equipo de transporte. Dichas empresas, las más dinámicas en materia de inversión extranjera directa en industrias globales durante el decenio de 1980, prácticamente no prestaron atención a América Latina.

Las actividades de las empresas transnacionales del Japón en el sector manufacturero del Asia en desarrollo se concentraron principalmente en dos áreas de complejidad tecnológica relativa: la maquinaria eléctrica y el equipo electrónico (ventas de 10400 millones de dólares, que representaron $27 \%$ de todas las ventas de las empresas transnacionales del Japón en esa industria en 1989) y el equipo de transporte (6000 millones de dólares en ventas, correspondientes a $28 \%$ de todas las ventas de las empresas transnacionales del Japón en esa industria en ese mismo año). Quizá convenga también mencionar las operaciones de las empresas transnacionales del Japón en el sector de la maquinaria no eléctrica de los países en desarrollo de Asia - aunque sus ventas en 1989 sólo alcanzaron a 1400 millones de dólares-, a causa de la importancia de la inversión extranjera directa realizada durante los años ochenta (cuadro 3 ).

Las filiales con capital mayoritariamente estadounidense de empresas transnacionales de ese país en estas dos regiones se concentraron sólo en tres sectores de relativa complejidad tecnológica: el equipo de transporte en América Latina (ventas por 9900 millones de dólares, correspondientes a 9\% del total de las ventas de las empresas transnacionales estadounidenses en dicha industria en 1989); la maquinaria eléctrica y el equipo electrónico en los países en desarrollo de Asia (ventas por 9200 millones de dólares, correspondientes a $25 \%$ de todas las ventas de las transnacionales de Estados Unidos en esa industria en 1989), y la maquinaria no eléctrica en América Latina (ventas por 5800 millones de dólares, equivalentes a $6 \%$ de las ventas totales de las transnacionales estadounidenses en esa rama 1989).

En comparación con las operaciones de las empresas transnacionales del Japón en los mismos sectores de ambas regiones, hay dos características de las transnacionales estadounidenses que destacan.

En primer lugar, sus actividades más importantes en América Latina - vinculadas al equipo de transporte y la maquinaria no eléctrica- son de importancia relativamente secundaria y tienden a hacerse más marginales dentro de la estructura global de las empresas transnacionales $(6 \%$ a $9 \%$ de todas las ventas de las transnacionales estadounidenses que operaban en esos sectores en 1989 , contra $8 \%$ a $13 \%$ en 1982). Al mismo tiempo, las actividades de dichas transnacionales en el sector de la maquinaria eléctrica en el Asia en desarrollo han adquirido significación en el contexto global de las empresas transnacionales (en 1989 originaron $25 \%$ de todas las ventas de las empresas transnacionales de Estados Unidos en dicha industria) y se expanden aceleradamente (desde un $12 \%$ de las ventas totales en 1977). En general, las empresas transnacionales estadounidenses habían estado perdiendo interés en América Latina.

En segundo lugar, el elevado componente de comercio exterior en las actividades de esas transnacionales en torno a la maquinaria eléctrica en 1989 indica que ellas no están necesariamente comprometidas a atender sólo al mercado local, como lo han hecho tradicionalmente. Aunque su componente de comercio exterior es considerablemente menor que en las actividades equivalentes de las transnacionales japonesas en el Asia en desarrollo, las transnacionales estadounidenses han creado una suerte de red para abastecer al mercado norteamericano y, en menor grado, a terceros países.

Por lo demás, si observamos la evolución de sus operaciones en América Latina en este sector industrial, vemos que mientras sus ventas locales disminuyeron a causa de la crisis de los años ochen- 
ta, sus ventas externas aumentaron sustancialmente (de $6 \%$ a $9 \%$ de las exportaciones totales de las empresas transnacionales estadounidenses que operaban en esa industria entre 1982 y 1989), en especial al mercado norteamericano. Las empresas transnacionales de Estados Unidos están tratando de adaptar sus operaciones en América Latina al nuevo orden industrial internacional, en el cual las redes regionales de abastecimiento representan un elemento importante para 1a competitividad internacional. Este es un avance de importancia para ellas; sin embargo, cabe señalar que sus exportaciones de maquinaria eléctrica y equipo electrónico desde América Latina a los Estados Unidos comprenden principalmente productos electrónicos de consumo (electrodomésti$\cos$, etc.), mientras que las que hacen desde los países en desarrollo de Asia hacia ese mismo mercado incluyen sobre todo computadores y productos conexos. De manera que dentro de la misma industria existen algunas diferencias de complejidad tecnológica entre las actividades de esas empresas transnacionales en el Asia en desarrollo y en América Latina, además de las diferencias antes mencionadas de dinamismo y de potencialidades para una mejor integración de sus redes empresariales globales .

Es evidente que la fuente de la inversión extranjera directa y de la tecnología influye en la naturaleza de la incorporación de la industria de países en desarrollo en el nuevo orden industrial internacional. $\mathrm{La}$ inversión extranjera directa y la transferencia de tecnología del Japón hacia los países en desarrollo de Asia han producido mayores efectos positivos que sus contrapartes estadounidenses en América Latina, como queda de manifiesto en las diferencias antes señaladas.

\section{La importancia de la forma de la inversión extranjera directa y de la transferencla de tec- nología}

En cuanto a la forma que han tomado la inversión extranjera directa y la transferencia de tecnología, hay dos ejemplos que sirven a nuestros propósitos.

\section{i) La industria de la maquinaria eléctrica y los equipos electrónicos}

La vertiente industrial de la revolución de la microelectrónica se centró indiscutiblemente en los países en desarrollo de Asia, los que se convirtieron en centro de abastecimiento y plataforma de exportación para las empresas transnacionales, tanto japonesas como estadounidenses que operaban en esta rama industrial. Esto indica que, en igualdad de condiciones, el comportamiento más reciente de las transnacionales de uno y otro país es convergente en lo que se refiere a las operaciones manufactureras regionales en algunos países en desarrollo. Además, las actividades en América Latina de las transnacionales estadounidenses que participan en este sector al parecer tratan de adaptarse mediante la transformación de sus actividades orientadas al mercado local en operaciones de fabricación de componentes y ensamblaje para exportación a los Estados Unidos.

Cabe hacer hincapié, sin embargo, en que hay varias diferencias fundamentales entre el comportamiento de las transnacionales estadounidenses y el de las japonesas en sus respectivas redes regionales, y que tales diferencias influyen considerablemente en las oportunidades y beneficios a los que pueden acceder los países en desarrollo incorporados o asociados a ellas. Por ejemplo, la red de empresas transnacionales de los Estados Unidos se basa más directamente en la propiedad mayoritaria de sus filiales locales. Las transnacionales de Japón, por su parte, utilizan diversas opciones de participación minoritaria y no accionaria, y en especial la concesión de licencias o la subcontratación. Estas dos últimas formas han servido en los países en desarrollo para facilitar el avance tecnológico de las empresas locales, en el marco de una estrategia del gobierno nacional de incorporación al nuevo orden industrial internacional, especialmente en lo que toca a las corrientes de comercio e inversión.

Respecto de este tema cabe decir que si bien las cuatro economías asiáticas de industrialización reciente han avanzado en esa incorporación, especialmente en la industria electrónica, sus estrategias han tenido diferencias que cabe destacar. Hong Kong y Singapur han seguido lo que puede calificarse de estrategia centrada en las empresas transnacionales, mientras que la República de Corea y, en menor grado, la provincia china de Taiwán se han ceñido a una estrategia de asociación con tales empresas. En ambas variantes se comenzo con el ensamblaje a bajo costo para transnacionales orientadas a la exportación, a menudo recurriendo a zonas de procesamiento de exportaciones; sin embargo, la variante Corea/Taiwán fue más allá que la Hong Kong/Singapur al utilizar la demanda interna para ayudar a los proveedores nacionales a competir con productos de sus propias marcas (Mody, 1989; Business Week, 1993). 
En lo que se refiere a la importancia de las empresas, la variante Hong Kong/Singapur utilizó la inversión extranjera directa como elemento principal en la formación de capital interno, con cifras que subieron de $15.2 \%$ y $25.5 \%$ durante el período 1985 1987, mientras que dichos niveles en la variante Taiwán/Corea fueron considerablemente más bajos: $3.3 \%$ y $1.4 \%$, respectivamente (CET, 1992). La proporción del monto de la inversión extranjera directa en el sector manufacturero que se destinó a la rama electrónica fue aproximadamente similar en estas economías - cerca de la tercera parte del total, salvo en Hong Kong, donde llegó al $46 \%$--pero la índole y la procedencia de la inversión variaron considerablemente; estas variaciones influyeron mucho en los beneficios para los países receptores de esta participación extranjera.

En general, la inversión extranjera directa en esta rama industrial en Hong Kong y Singapur provino principalmente de los Estados Unidos, y generalmente en forma de participación mayoritaria en el capital de filiales de empresas transnacionales. En la República de Corea y, en menor grado, en la provincia china de Taiwán, tal inversión provino básicamente de Japón, a menudo como participación minoritaria en el capital o nuevas formas no accionarias de inversión (Oman, 1984 y 1989; Germidis, 1980). Por tal razón, las firmas electrónicas con mayores ventas de Hong Kong (Digital, General Electric, Hewlett-Packard, Honeywell e IBM) y Singapur (Seagate, Philips y National Semiconductors) son generalmente subsidiarias de empresas transnacionales estadounidenses. En cambio, las compañías electrónicas más importantes de la República de Corea (Samsung y Goldstar) y de la provincia china de Taiwán (Tatung, Sampo y Teco) son nacionales en la actualidad. La variante Corea/Taiwán ha tenido mayor éxito en estimular la formación de conglomerados industriales incipientes que proveen de bases tecnológicas más firmes a las empresas nacionales para ponerse al día (Ernst y O'Connor, 1992, cap.V; OCDE, 1988). Esta pareciera ser una estrategia útil, aunque difícil, para los países en desarrollo con demanda interna suficiente para nutrir la capacidad competitiva de firmas nacionales mediante sus asociaciones con empresas transnacionales que las proveen de la tecnología necesaria.

El éxito de los países de industrialización reciente de Asia en la industria de la maquinaria eléctrica pareciera ofrecer a los países en desarrollo ejemplo muy pertinente de incorporación al nuevo orden industrial internacional, porque se basa en una com- petitividad internacional cada vez mayor que ha generado importantes corrientes de comercio e inversión. Merece destacarse que la red regional asiática centrada en las transnacionales de Japón ha ofrecido a algunos países en desarrollo oportunidades significativas para integrarse más en el sistema industrial internacional, aprovechando la fase de la inversión extranjera directa de Japón (Lawrence, 1992) llamada de industrialización por subcontratación y actividades de ensamblaje, y la etapa del multinacionalismo caracterizada por el transplante de las operaciones de ensamblaje (Ozawa, 1992, pp. 52-53).

Las estrategias de núcleos regionales aplicadas por las empresas transnacionales japonesas en la industria eléctrica y electrónica parecen seguir en la actualidad una modalidad de fuertes eslabonamientos aguas arriba (abastecimientos) de Japón con las filiales asiáticas, las que luego cumplen la doble función de i)vender artículos terminados en los mercados locales y regionales (inversiones destinadas a sustituir importaciones) y ii) exportar a filiales de la Tríada para sufragar sus propias operaciones con insumos de bajo costo (inversiones racionalizadas) (CET, 1991a; The Economist, 1993). Esto ofrece a un grupo relativamente pequeño de países en desarrollo la oportunidad de integrar más cabalmente su estructura productiva para la industria electrónica en la estructura de los segmentos más dinámicos de la industria internacional. Los elevados volúmenes de ventas y la existencia de mercados de exportación de mayor tamaño han permitido crear redes de abastecimiento regionales, en las que las operaciones integradas en varios países de Asia se proveen mutuamente de insumos. La inversión extranjera directa hacia este sector en los países recién industrializados de Asia, en cuatro países de la ASEAN y en otros países en desarrollo adquiere fuerza (Whitmore, Lall y Hyun, 1989). Así, algunos países asiáticos de industrialización reciente han superado su condición de ser sólo proveedores de las transnacionales locales y se han convertido en auténticos competidores en la producción de determinadas líneas de maquinaria eléctrica y de equipo electrónico, lo que coincide con to sugerido por el símil de los ánsares en vuelo.

\section{ii) La industria automovilística}

Esta industria, en la cual tiene especial importancia la forma que reviste la inversión extranjera directa o la transferencia de tecnología, es otro ejemplo de la clara diferencia entre una industria de América Latina centrada en las empresas transnacionales, y 
una de Asia asociada a dichas empresas. Aquí se considerará principalmente la propiedad del capital accionario, ya que los temas más sinuosos de la subcontratación y de otras formas de relación con los proveedores distintas de la participación en el capital social, desbordan los límites del presente artículo.

En 1986 doce grandes transnacionales de la rama automovilística poseían cerca de $90 \%$ de la capacidad total de las empresas transnacionales para producir automóviles en los países en desarrollo (cuadro 5). Cerca de la mitad de dicha capacidad correspondía a subsidiarias o a filiales en cuyo capital las transnacionales tenían participación mayoritaria. La otra mitad correspondía a filiales en las que esa participación era minoritaria, o a formas de asociación que no suponían participación en el capital social. En números redondos, dicha capacidad productiva se distribuía de manera más o menos pareja entre las transnacionales de Japón, Europa y los Estados Unidos. Pero la capacidad productiva de las transnacionales estadounidenses y europeas que operaban en los países en desarrollo estaba representada principalmente por subsidiarias o por filiales con capital transnacional mayoritario, mientras que la de las transnacionales japonesas co- mespondía casi exclusivamente a formas de asociación con capital transnacional minoritario o a arreglos que no incluían la participación de la empresa transnacional en el capital social.

La capacidad productiva de las empresas automovilísticas transnacionales de los Estados Unidos y Europa en los países en desarrollo se concentraba (85\%) en América Latina, en tanto que la de las transnacionales japonesas se concentraba aún más $(89 \%)$ en Asia (cuadro 6). Más notable aún es que la mayor parte $(88 \%)$ de la capacidad de producción de las empresas automovilísticas transnacionales de los Estados Unidos y Europa se hallaba en subsidiarias o en filiales en cuyo capital dichas empresas tenían participación mayoritaria, mientras que la capacidad de las japonesas en Asia se daba casi exclusivamente a través de asociados en cuyo capital tenían participación minoritaria, o de asociaciones que no significaban participación en el capital social. Estos datos confirman que la industria automovilística de América Latina puede considerarse centrada en las empresas transnacionales, mientras que la de los países en desarrollo de Asia puede considerarse asociada a las empresas transnaciona-

CuAdros

Empresas transnacionales fabricantes de automóviles: operaciones en los países en desarrollo, según la forma de la inversión, 1986

(Miles de unidades')

\begin{tabular}{|c|c|c|c|c|}
\hline & $\begin{array}{r}\text { Inversión } \\
\text { mayoritaria }\end{array}$ & $\begin{array}{r}\text { Inversion } \\
\text { minoritaria }\end{array}$ & $\begin{array}{r}\text { Sin inversión } \\
\text { en el capital social }\end{array}$ & Total \\
\hline \multicolumn{5}{|c|}{ Empresas transnacionales } \\
\hline Mitsubishi & 6.7 & 483.9 & 27.9 & 518.5 \\
\hline Volkswagen & 482.6 & 14.3 & 6.5 & 503,4 \\
\hline General Motors & 374.8 & 63.0 & 13.7 & 451.5 \\
\hline Ford & 355.6 & 4.1 & 2.9 & 342.5 \\
\hline Fiat & 168.5 & 74.9 & 44.3 & 287.7 \\
\hline Nissan & 78.2 & 66.7 & 47.7 & 192.5 \\
\hline Mazda & 9.5 & 115.9 & 43.5 & 1689 \\
\hline Suzuki & - & 98.9 & 36.3 & 135.2 \\
\hline Daimler-Benz & 48.4 & 60.1 & 12.0 & 120.5 \\
\hline Renault & 56.6 & 26.6 & 25.3 & 108.5 \\
\hline Toyota & 29.3 & 13,2 & 52.7 & 95.2 \\
\hline Chrysler & 87.3 & 4.8 & 0.3 & 92,6 \\
\hline Todas las demás & 11.3 & 179.5 & 158.9 & 349.7 \\
\hline \multicolumn{5}{|l|}{$\begin{array}{l}\text { Distribución por } \\
\text { región de origen }\end{array}$} \\
\hline Japón & 125.5 & 841.2 & 304.8 & 1271.5 \\
\hline Europa & 763.3 & 234.8 & 137.1 & 1135.2 \\
\hline Estados Unidos & 802 & 129.8 & 30.0 & 959.9 \\
\hline Total & 1689.0 & 1205.8 & 471.8 & 3366.6 \\
\hline
\end{tabular}

Fuente: Cálculo basado en Charles Oman, New Forms of Investment in Developing Country Industries: Mining, Petrochemicals, Automobiles, Textlles, Food, París, OCDE, 1989, cuadro 4.22, p. 201. Véanse en el cuadro original las definiciones y las notas aclaratorias. 
CUADRO 6

\section{Empresas transnacionales fabricantes de automóviles en los países en desarrollo, según la reglón receptora y la forma de la inversión (Miles de unidades)}

\begin{tabular}{ccccc}
\hline & América Latina & & \multicolumn{2}{c}{ Economías de industrialización reciente de Asia } \\
\hline $\begin{array}{c}\text { Inversión } \\
\text { mayoritarial }\end{array}$ & $\begin{array}{c}\text { Inversión } \\
\text { minoritaria } 0 \\
\text { sin participación } \\
\text { en el capital social }\end{array}$ & Total & $\begin{array}{c}\text { Inversión } \\
\text { mayoritaria }\end{array}$ & $\begin{array}{c}\text { Inversión } \\
\text { minoritaria o } \\
\text { sin participación } \\
\text { en el capital }\end{array}$ \\
\hline
\end{tabular}

Empresas

transnacionales

Mitsubishi

Volkswagen

General Motors

Ford

Fiat

Nissan

Mazda

Suzuki

Daimler-Benz

Renault

Toyota

Chrysler

Todas las demás

Distribucion por

region de origen

Japón
Europa
Estados Lnidos
Total

$\begin{array}{rrr}- & 1.3 & 1.3 \\ 482.6 & 5.3 & 487.9 \\ 368.5 & 9.2 & 377.7 \\ 305.6 & 0.2 & 305.8 \\ 168.0 & 71.4 & 239.4 \\ 78.2 & 4.0 & 82.2 \\ - & 13.7 & 13.7 \\ - & 1.0 & 1.0 \\ 48.4 & 1.5 & 49.9 \\ 54.1 & 26.2 & 80.3 \\ 8.3 & 19.4 & 27.7 \\ 87.5 & 5.1 & 92.6 \\ 8.2 & 52.9 & 61.1\end{array}$

$\begin{array}{rr}6.7 & 508.6 \\ - & 8.5 \\ 0.3 & 61.3 \\ 30.0 & 5.9 \\ - & 29.4 \\ - & 107.2 \\ 9.5 & 144.9 \\ - & 133.4 \\ - & 69.6 \\ - & 8.9 \\ 21.0 & 44.9 \\ - & - \\ 2.5 & 226.5\end{array}$

515.3

8.5

61.6

35.8

29.4

107.2

154.4

133.4

69.6

8.9

65.9

229.0

Fuente: Calculo basado en Charles Oman, New Forms of Investment in Developing Country Industries: Mining, Petrochenicals, Automobiles, Textiles, Food, París, oCJE, 1989, cuadro 4.23, p. 201. Véanse en el cuadro original las definiciones y las notas aclaratorias.

les: de esta diferencia derivan aparentemente consecuencias importantes para las industrias automovilísticas predominantes en los países en desarrollo de estas regiones.

Cabe reiterar que el origen y la forma de participación de las empresas transnacionales en la industria automovilística de los paises en desarrollo no constituyen los únicos factores que explican el éxito relativo de la experiencia de los países en desarrollo de Asia o la declinación relativa en el caso de América Latina. Por lo demás, existen diferencias importantes dentro de la propia región latinoamericana. La exitosa reestructuración de la industria automovilística mexicana es una clara excepción a esta generalización que vincula el desempeño económico relativo con la forma, el origen y el nivel de la participación extranjera. Las subsidiarias de las empresas transnacionales que operan en México exportaron más de 340000 vehículos a los Estados Unidos en 1992
(AMIA, 1993, p. 33) y la industria mexicana de autopartes (principalmente motores) suministró el $12 \%$ de las importaciones de componentes para automóviles del mercado de los Estados Unidos en 1989 (Bowring, 1990, p. 61). Sin embargo, de este análisis se desprende también que el resto de la industria automotriz de América Latina se halla en dificultades, aparentemente, al parecer por ser una mala imitación de las empresas automotrices transnacionales relativamente menos eficientes de los Estados Unidos y Europa: necesita, más que sus progenitores, hacer una urgente reestructuración y superar los problemas entre fabricantes y proveedores que también parecen entorpecer su capacidad de competir en el plano internacional (Bowring, 1990, cap. III).

En Asia, las estrategias de las transnacionales automotrices japonesas han dado impulso a procesos locales acelerados de modernización tecnológica que se han traducido, por una parte, en eficiencias pro- 


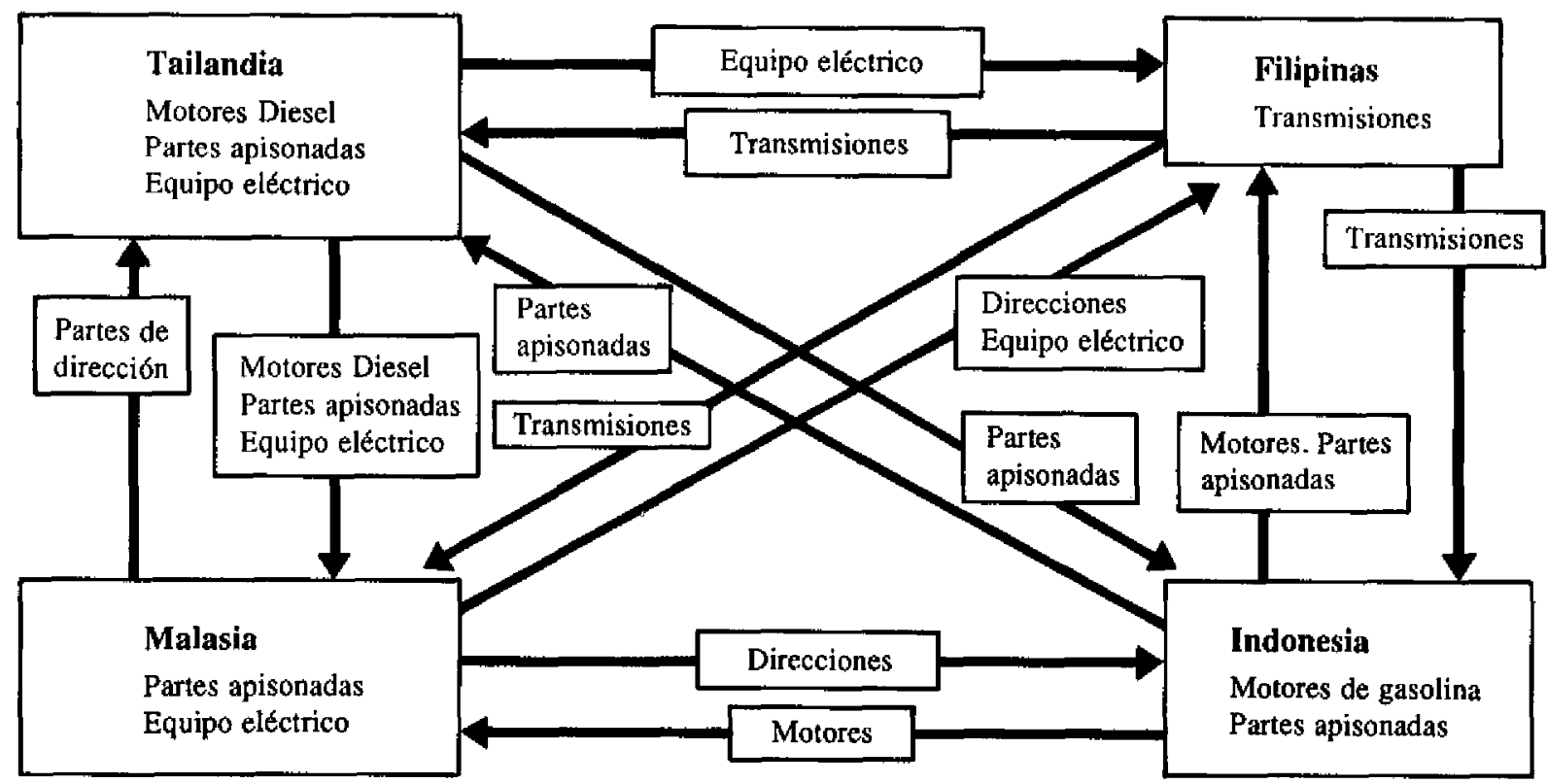

Fuente: Part exchange, Far Eastem Economic Review, 21 de septiembre de 1989, p. 73

ductivas y ventajas comerciales derivadas de la especialización, como lo ilustra el caso de la Toyota (gráfico 1), y por otra, en la producción de automóviles del Asia en desarrollo, como los Hyundai, Kia, y otros. La revista Motor Trend recientemente designó un modelo de Hyundai como uno de los diez mejores automóviles importados por los Estados Unidos. Algunas transnacionales automotrices del Asia en desarollo han llegado incluso a la etapa de invertir en instalaciones productivas en Norteamérica y Europa para participar "desde adentro" en la industria automovilística global.

La dinámica industria automovilística de Asia muestra una envidiable fortaleza competitiva. La de América Latina -con la salvedad, hasta cierto punto, del componente mexicano que se halla en proceso de integración a la industria norteamericana- no disfruta al parecer de tales ventajas y corre el riesgo de ser víctima del remezón que afecta a las empresas automovilísticas transnacionales a nivel mundial.

\section{IV}

\section{Observaciones finales}

Sería una burda exageración pretender que las diferencias evidentes y significativas en las experiencias industriales de América Latina y de los países en desarrollo de Asia, y en la índole de su incorporación al nuevo orden industrial internacional, se han debido exclusivamente a las empresas transnacionales, en general, y al origen y la forma de la inversión extranjera directa y de la transferencia de tecnología forá- nea, en particular. También sería una manifiesta simplificación sugerir que tales factores no fueron decisivos para explicar esta situación.

En un mundo en que el poder decisorio se traslada hacia las empresas transnacionales más importantes y escapa a los gobiernos, la evolución del mercado internacional para determinados productos y las estrategias de las empresas transnacionales para orga- 
nizar su producción en términos globales contribuirán cada vez más a determinar la ubicación espacial de la industria, las transferencias de tecnología y las modalidades del comercio. Los países en desarrollo se hallan en una situación difícil porque hoy las empresas transnacionales pueden escoger entre ellos. Disminuido así su poder de negociación, los factores que afectan a la competitividad internacional relativa de una industria nacional se vuelven elementos decisivos para que esos países se incorporen al nuevo orden industrial internacional.

Dentro de este nuevo orden, el origen y la forma de la inversión extranjera directa y de la transferencia de tecnología, hoy como en el pasado, influyen considerablemente en las probabilidades de éxito de los países en desarrollo. La experiencia del Asia en desarrollo, basada en gran parte en la inversión extranjera directa y la transferencia de tecnología japonesas, a menudo a través de una participación minoritaria en el capital de los asociados locales o de concesiones de licencias o convenios de abastecimiento como la subcontratación de insumos o de equipos terminados (original equipment manufactures) ha llevado a la industria asiática a un nivel de competitividad internacional relativamente mayor que el logrado por América Latina con inversión extranjera directa y tecnología de origen principalmente estadounidense, generalmente a través de subsidiarias o de filiales con participación mayoritaria del capital transnacional. Esto es particularmente cierto en las industrias tecnológicamente más complejas, como lo demuestran con claridad los sectores de la maquinaria eléctrica y los equipos eléctronicos y la industria automovilística.

El origen y la forma de la inversión extranjera directa y de la transferencia de tecnología han contribuido de manera muy significativa a que la industria de los países asiáticos en desarrollo haya dominado técnicas complejas, haya alcanzado niveles impresionantes de eficiencia productiva mediante la especialización y haya penetrado mercados internacionales exigentes. Las ventajas competitivas de los países en desarrollo de Asia atrajeron del exterior la inversión directa y la tecnología más dinámicas y las formas que éstas tomaron fueron más propicias para que la industria local se incorpora más cabalmente al nuevo orden industrial internacional. Estos países, por lo tanto, se han adaptado mejor a dicho nuevo orden.

Estos mismos factores han tenido en cambio mucho que ver con las dificultades que ha enfrentado la industria de América Latina. Una inversión extranjera directa y una tecnología foránea menos dinámicas, en el contexto de un modelo cerrado de industrialización basado en la sustitución de las importaciones, produjo una industria volcada hacia adentro, ineficiente y no competitiva. La transferencia de tecnología por medio de subsidiarias o de filiales en las que tenía participación mayoritaria el capital transnacional no ayudo a la industria local a asimilar, adaptar y mejorar tecnologías dinámicas. Por el contrario, las prácticas manufactureras óptimas de América Latina, incluso en las subsidiarias de empresas transnacionales, no sólo se hallan lejos de la frontera tecnológica, sino que a menudo se aproximan a la obsolescencia. El aumento de las exportaciones manufactureras suele lograrse a expensas del valor agregado nacional en el proceso de producción, luego que la crisis de los años ochenta provocó el estancamiento o el colapso de la inversión en la región, justamente en un momento en que la modernización tecnologica se convertía en el acicate para incorporar a los países en desarrollo al nuevo orden industrial internacional. Para competir con los ánsares voladores, los patos deben primero levantar el vuelo.

(Traducido del inglés)

\section{Bibliografia}

AMIA (Asociación Mexicana de la Industria Automotriz) (1993): La industria automotriz terminal mexicana en 1992, Boletín No. 325, México, D.F, enero.

Blomström, M. (1990): Transnational Corporations and Manufacturing Exports from Developing Countries, Nueva York, Naciones Unidas, Centro de las Naciones Unidas sobre las Empresas Transnacionales (CET). Publicación de las Naciones Unidas, No. de venta E.90.II.A.21.

Bowring, A. (1990): The US Automotive Aftermarket: Opportunities and Constraints for Developing Country Suppliers, Industry series paper, No. 39, Washington, D.C., Banco Mundial, junio.
Business Week (1993): Taiwan: the arms dealer of the computer wars, Nueva York, McGraw-Hill, Inc, 28 de junio.

Cantwell, J.A. y J.H. Dunning (1991): Multinational enterprises, technology and the competitiveness of European industries, Aussenwirtschaft, No. 46, Heft 1, Zürich, Verlag Rüger, abril.

CET (1991a): World Investment Report 1991. The Triad in Foreign Direct Investment, Nueva York. Publicación de las Naciones Unidas, No. de venta E.91.II.A.12.

(1991b): Investment in Asia quintuples in the 80s, Transnationals, vol. 3, No. 3, Nueva York, octubre.

(1992): World Investment Directory 1992. Asia and the Pa- 
cific, vol. 1, Nueva York. Publicación de las Naciones Unidas, No. de venta E.92,II.A.11.

(en prensa): World Investment Directory 1993, Latin America and the Caribbean, vol. 4, Nueva York

Chandler Jr., Alfred D. (1990): Scale and Scope: the Dynamics of Industrial Capitalism, Cambridge, Mass., Harvard Unjversity Press.

Dahlman, C.J, y P. Brimble (1990): Technology Strategy and Policy for Industrial Competitiveness: a Case Study of Thailand, Industry series paper, No. 24, Washington, D.C., Banco Mundial.

Encarnation, Dennis (1992): Rivals Beyond Trade: America versus Japan in Global Competition, Nueva York, Cornell University Press.

Ernst, D. y D. O'Connor (1989): Technology and Global Competition. The Challenge for Newly Industrialising Economies, París, Organización de Cooperación y Desarrollo Económicos (OCDE), Centro de Desarrollo.

(1992): Competing in the Electronics Industry: the Experience of Newly Industrialising Economies, París, OCDE, Centro de Desarrollo.

Estados Unidos, Departamento de Comercio (1981): US Direct Investment Abroad: 1977 Benchmark Survey Data, Washington, D.C., abril.

(1985): US Direct Investment Abroad 1982 Benchmark Survey Data, Washington, D.C., diciembre.

(1988): Defining and measuring international direct investment: a methodological review, International Direct Investment : Global Trends and the US Role, apéndice G, Washington, D.C., noviembre.

(1990): Survey of Current Business, vol. 70, No. 8, Washington, D.C., agosto.

(1991): US Direct Investment Abroad: 1989 Benchmark Survey Data, Washington, D,C., octubre.

Far Eastem Economic Review (1989): Part exchange, 21 de septiembre.

FMI (Fondo Monetario Internacional) (1992): Notable crecimiento de las economías en desarrollo del Asia, FMI boletín, vol. 21, No. II, Washington. D.C., 1 de junio.

Fukusaku, Kiichiro (1992): Economic Regionalization and Intraindustry Trade: Pacific Asian Perspective, Technical papers, No. 53, París, OCDE, Centro de Desarrollo.

Germidis, D. (ed.) (1980): International Subcontracting, A New Form of Investment, París, OCDE

Japón, Ministry of International Trade and Industry (1986): Benchmark Survey on Japanese Companies Foreign Activities: Compendium on Foreign Activity Data, Tokio.

(1991): Benchmark Survey on Japanese Companies Foreign Activities: Compendium on Foreign Activity Data, Tokio.

Jenkins, R. (1990): Comparing foreign subsidiaries and local firms in LDCs: theoretical issues and empirical evidence, The Journal of Development Studies, vol. 26, No. 2, Londres, Frank Cass \& Co. Ltd.

Kerai Koho Center (1984): Japan 1984: An International Comparison, Tokio.

(1992): Japan 1992: An International Comparison. Tokio.

Kojima, K. (1975): International trade and foreign investment: substitutes or complements, Hitotsubashi Journal of Economics, vol, 16, No. 1, Tokio, Hitotsubashi University, junio.

Lawrence, R.Z. (1992): An analysis of Japanese trade with developing countries, UNCTAD Review, No. 3, Ginebra, Conferencia de las Naciones Unidas sobre Comercio y Desarrollo (UNCTAD). Publicación de las Naciones Unidas, No. de venta E.91.II.D.21

Minato, T. (1986): The Japanese system of subcontracting and interfirm communication, Linkage Effects and Small Industry Development. Tokio, Asian Productivity Organization.
Mody, A. (1989): Institutions and Dynamic Comparative Advantage: Electronics Industry in South Korea and Taiwan, Industry series paper, No. 9, Washington, D.C., Banco Mundial, Departamento de Industria y Energía.

Mortimore, Michael (1992): El nuevo orden industrial internacional, Revista de la CEPAL, No. 48, LC/G. 1748-P, Santiago de Chile, CEPAL, diciembre.

Naciones Unidas (1991): Industrial Restructuring in Asia and the Pacific. In Particular with a View to Strengthening Regional Co-operation, Bangkok, Comisión Económica y Social para Asia y el Pacífico (CESPAP)/Gobieno de la República de Korea, marzo.

Newfarmer, R. y W. Mueller (1975): Multinational Corporations in Brazil and Mexico: Structural Sources of Economic and NonEconomic Power, Report to United States Senate, Washington, D.C., U.S. Government Printing Office.

OCDE (Organización de Cooperación y Desarrollo Económicos) (1987): Recent Trends in International Direct Investment, París.

(1988): The Newly Industrializing Countries: Challenge and Opportunities for $O E C D$ Industries, París.

(1992): Technology and the Economy: The Key Relationships, Paris.

Oman, C. (1984): New Forms of International Investment in Developing Countries, París, OCDE.

(1989): New Forms of Investment in Developing Country Industries: Mining, Petrochemicals, Automobiles, Textiles, Food, París, OCDE.

Ozawa, Terumoto (1992): Foreign direct investment and economic development, Transnational Corporations, vol. 1, No. 1, Nueva York, Naciones Unidas, febrero.

Papageorgiou, D., A.M. Choksi y M. Michaely (1990): Liberalizing Foreign Trade in Developing Countries: the Lessons of Experience, Washington, D.C., Banco Mundial, septiembre.

(1992) Technology and The Economy: The Key Kelatronchips, Pars.

Patterson, N. (1990): The world statistical discrepancy on foreign direct investment flows: a preliminary review, WPMCF $2 / 4$, Washington, D.C., FMI, 18 de mayo, mimeo.

Porter, Michael (1990): The Competitive Advantage of Nations, Nueva York, Free Press.

Sato, Y. (1986): Formation of the Japanese style subcontracting production system: historical perspective and socio-economic imperatives, Linkage Effects and Small Industry Development, Tokio, Asian Productivity Organization.

Stekler, L.E. y G.V.G. Stevens (1991): The Adequacy of US Direct Investment Data, International finance discussion papers, No. 401, Washington, D.C., Junta de Gobernadores, Sistema de la Reserva Federal, junio.

Teece, David (ed.) (1987): The Competitive Challenge: Strategies for Industrial Innovation and Renewal. Cambridge, Mass., Ballinger Publishing Co.

Ten Kate, A. (1992): Trade liberalization and economic stabilization in Mexico: lessons of experience, World Development, vol. 20, No. 5, Nueva York, Pergamon Press, mayo.

The Economist (1991): A survey of Asia's emerging economies: where tigers breed, vol. 321, No. 7733, Londres, 16 de noviembre.

(1992): Overseas Chinese. A driving force, vol. 324, No. 7768, Londres, 18 de julio.

(1993): Japanese manufacturing. Asian promise, vol. 327, No. 7815 , Londres, 12 de junio.

Thurow, Lester (1992): Head to Head: the Conting Economic Battle Among Japan, Europe and America, Nueva York, William Morrow \& Co. Inc.

UNCTAD (Conferencia de las Naciones Unidas sobre Comercio y Desarrollo) (1993): World Investment Report 1993. Trans- 
national Corporations and Integrated International Production, Nueva York, Programa sobre las Empresas Transnacionales. Publicación de las Naciones Unidas, No. de venta E.93.II.A.14.

Whitmore, K., S. Lall y Jung-Taik Hyun (1989): Foreign Direct Investment from the Newly Industrialized Economies, In- dustry series paper, No. 22, Washington, D.C., Banco Mundial, Departamento de Industria y Energía, dicicmbre. Whitmore, K. y Jung Taik Hyun (1989): Japanese Direct Foreign Investment: Patterns and Implications for Developing Countries, Industry series paper, No. 1, Washington, D.C., Banco Mundial, febrero. 